\title{
Rural-Urban Variation in COVID-19 Experiences and Impacts among U.S. Working-Age Adults
}

\author{
Shannon M. Monnat \\ Lerner Center Director and Lerner Chair for Public Health Promotion \\ Associate Professor of Sociology \\ Maxwell School of Citizenship and Public Affairs \\ Syracuse University \\ smmonnat@syr.edu
}

Keywords: COVID-19, rural, urban, health

Forthcoming in The ANNALS of the American Academy of Political and Social Sciences 
Funding: The author acknowledges support from two research networks funded by the National Institute on Aging (R24 AG065159 and 2R24 AG045061), the NIA-funded Center for Aging and Policy Studies at Syracuse University (P30AG066583), the NICHD-funded Population Research Institute at Penn State (P2CHD041025), the USDA Agricultural Experiment Station Multistate Research Project: W4001, Social, Economic and Environmental Causes and Consequences of Demographic Change in Rural America, and the Syracuse University Lerner Center for Public Health Promotion. 


\begin{abstract}
This study investigates rural-urban continuum differences in COVID-19 experiences and impacts to physical and mental health, social relationships, employment, and financial hardship among U.S. working-age adults (18-64) from the National Wellbeing Survey collected in February and March $2021(\mathrm{~N}=3,933)$. Most respondents (58\%) reported that COVID-19 has had a negative impact on their lives. Residents of rural counties adjacent to metro areas reported the worst outcomes. They were more likely than residents of large urban counties to report testing positive for coronavirus, living with someone who tested positive, having a close friend or family member outside of the household test positive, having a close friend or family member hospitalized, seeking treatment for anxiety or depression, being late paying rent, mortgage, and other bills, not being able to afford groceries or other necessities, and getting a loan from family or friends. Recovery policies must consider geographic variation in COVID-19 vulnerability and impacts.
\end{abstract}


In the early weeks of the spread of the COVID-19 pandemic in the U.S., I suggested that COVID-19 could hit rural areas harder than urban areas (Monnat 2020). I argued that while lower population density may protect rural areas from spread early on, both the population composition and contextual features of rural communities put them at risk of higher rates of mortality from COVID-19 once the virus spread to those places. I also suggested that the longerterm health and economic impacts could be worse in rural than in urban areas. Since then, a growing body of research has shown higher cumulative COVID-19 infection and mortality rates in rural counties (Cromartie et al. 2021; Huang et al. 2021; Pender 2021; Sun et al. 2021) but potentially less severe labor market impacts (Brooks et al. 2021; Cho et al. 2020; Cromartie et al. 2021). However, rural areas are not homogenous, and there has also been significant within-rural variation in COVID-19 spread and mortality rates (Cheng et al. 2020; Cohen 2020; Cromartie et al. 2020; Sun et al. 2021).

The consequences of COVID-19 extend far beyond the deaths it has caused. The pandemic itself, and the spread mitigation policies it prompted, have adversely affected physical and mental health (Brodeur et al 2021; Czeisler et al. 2020a; Gassman-Pines et al. 2020; Killgore et al. 2020, McPhee et al. 2020, Twenge and Joiner 2020), led to employment loss and financial hardship (Board of Governors of the Federal Reserve System 2021; Congressional Research Service 2021; Horowitz et al. 2021;), disrupted family and social relationships (Calbi et al. 2021; Kovacs et al. 2021; Philpot et al. 2021), and disrupted health care access (Czeisler et al. 2020b). Existing research on the secondary impacts of the pandemic in the U.S. generally shows worse outcomes among non-Hispanic blacks, women, and individuals without a college degree (Collins et al. 2020; Dias 2021; Kesler 2021; Landivar et al. 2020; Montenovo et al. 2020; Perry et al. 2020). In a sample of rural residents of the western U.S. conducted in June 2020, Mueller et al. 
(2021) found significant negative self-reported impacts of the pandemic on employment, overall life satisfaction, mental health, and economic outlook, with half of rural Western respondents perceiving some level of negative impact on their lives. However, to my knowledge, there is no research examining metropolitan status differences in COVID-19 experiences and secondary outcomes for the U.S. overall. Over 46 million people live in rural America, including some the country's most economically- and health-vulnerable populations (Cromartie et al. 2021).

Identifying the geographically-differential impacts of the pandemic on wellbeing is essential for informing recovery policies and prevention strategies for future pandemics.

The lack of geographic identifiers and/or small nonmetro sample sizes in most national surveys that have assessed COVID-19 impacts prohibit examining within-rural differences. We address this limitation by leveraging a unique timely national survey of working-age adults that oversampled rural residents to identify rural-urban continuum differences in COVID-19 experiences and impacts along several measures of physical and mental health, social relationships, employment, and financial hardship.

\section{Rural Vulnerability to Negative COVID-19 Experiences and Impacts}

There are several individual-level differences between rural and urban residents and contextual differences between rural and urban areas that may drive differential vulnerability to COVID-19 and its secondary impacts. Rural populations are more socioeconomically vulnerable, with higher rates of poverty (Thiede et al. 2018) and underemployment (Jensen and Slack 2003; Slack et al. 2020), and lower levels of education (Carr and Kefalas 2009) and health insurance coverage (Gong et al. 2019). These factors may make them more vulnerable to COVID-19 related economic shocks and associated physical and psychological health consequences. On the 
other hand, recent research suggests that urban workers were less likely than their rural peers to be paid for missed work hours and more likely to be unable to work, unable to look for work, or to work remotely during COVID-19 (Brooks et al. 2021). Rural schools were also more likely to remain open or operated remotely for much shorter periods than urban schools (Gross and Opalka 2020), reducing burdens on rural parents to home-school children. Differences in labor markets and working conditions may have reduced rural employment impacts, while simultaneously increasing risk of disease transmission. Government-deemed essential industries like meatpacking, agriculture, and prisons are disproportionately located in rural areas, placing rural workers at increased risk of infections, even as they continued to earn paychecks (Hooks and Sawyer 2020; Peters 2020; Taylor, Boulos, and Almost 2020).

Rural populations are also sicker than urban populations. They report worse self-rated physical and mental health and have higher rates of most chronic diseases (Michael et al. 2014; Monnat and Beeler Pickett 2011; National Center for Health Statistics 2019; Peters 2020). Not only do these poor health profiles increase risk of dying from COVID-19 among those who contract it (Li et al. 2021; U.S. Centers for Disease Control and Prevention 2020), but they may also increase risk of secondary physical and mental health impacts from the pandemic. Risks may be exacerbated for those who delayed or forewent medical care due to limitations on elective procedures and/or concerns about contracting the virus. Even before COVID-19, rural residents faced challenges with accessing health care. Since January 2005, 181 rural hospitals have closed, with a record 19 closures in 2020 alone (Cecil G. Sheps Center 2021). Many of the rural hospitals that are available had less capacity to deal with surges in cases, limited medical personnel, and less access to ventilators and personal protective equipment for healthcare providers. COVID-19 testing rates were also lower in rural areas (Monnat 2020; Souch and 
Cossman 2021), increasing risk of community spread. These factors may all have secondary effects on physical and psychological health.

Finally, rural residents have been more resistant to engaging in preventive behaviors, such as mask wearing (Callaghan et al. 2021; Haischer et al. 2020), avoiding dining out (Callaghan et al. 2021), and getting vaccinated (Kaiser Family Foundation 2021). These factors may contribute to increased COVID-19 spread in rural communities but may also buffer against poor social and psychological health outcomes. Likewise, governors in rural states (those with lower population density) were slower to enact statewide state-at-home orders (Lin et al. 2021) and were less likely to enact physical distancing mandates (Adolph et al. 2021) than governors in more urban states. This may have reduced employment, economic, social, and psychological health impacts (at least in the short-term) but simultaneously increased risk of disease spread. Based on the differences described above, we might expect rural residents to face less severe employment and financial impacts but more severe physical and mental health impacts. However, rural areas are not homogenous. Some rural communities are more vulnerable than others to severe economic shocks and health crises. One specific delineating factor may be whether the rural community is adjacent to a metropolitan area. Among rural counties, COVID19 infection rates have been higher in those that are adjacent to metro areas compared to remote rural counties that do not neighbor a metro area (Cheng et al, 2020; Sun 2020; Zhang and Schwartz 2020). Other recent research shows that remoteness may have buffered certain types of rural communities, particularly those dominated by services and recreation based employment, from COVID-19 spread (Sun et al. 2021). COVID-19 may have had spillover effects from urban to adjacent rural communities due to employee and consumer commuting patterns. Likewise, the economic consequences of business closures in large urban hubs may cascade to workers and 
consumers in neighboring rural communities. Therefore, we might expect more severe COVID19 impacts on residents in rural communities adjacent to metro areas than among residents of remote rural communities.

This study examines rural-urban continuum differences in self-reported COVID-19 infection experiences as well as health, social, employment, and financial impacts among working-age adults. While COVID-19 deaths disproportionately affected older adults, researchto-date shows larger employment (Montenovo et al. 2020) and psychological impacts (Czeisler et al. 2020) on working-age adults. Working-age adults suffered nearly all of the excess mortality from causes other than COVID-19 in 2020, driven mostly by drug overdoses (Glei 2021). They also experienced the brunt of employment disruption and role strain related to work, family, caretaking, and homeschooling (Collins et al. 2020; Kesler 2021; Landivar et al. 2020; Montenovo et al. 2020), portending severe impacts on physical and mental health and social and financial wellbeing in this age group.

\section{Data and Variables}

Individual-level data on COVID-19 experiences and perceived impacts come from the National Wellbeing Survey (NWS) (Monnat and Rhubart 2021). The NWS is a national crosssectional survey of 4,014 U.S. adults ages 18-64 designed by researchers in the Syracuse University Lerner Center for Public Health Promotion and conducted from February 1 to March 18, 2021. The sample includes respondents from all 50 states and the District of Columbia representing 1,430 U.S. counties. We designed the survey using several validated measures from other national surveys. The original aim of the survey was to collect data on adult physical, mental, psychological, and social health and well-being, with most questions constructed before 
COVID-19 hit in 2020. With the arrival of COVID-19, we delayed the launch of the survey and added a COVID-19 module (described below).

The survey was administered using Qualtrics Panels, an online survey platform that maintains a database of several million U.S. adults who volunteer to participate in surveys. Online panels are increasingly used in social science research due to efficiency, cost, timeliness, and data quality ${ }^{1}$ (Hays 2015). Qaltrics recruits Panel members from various sources, including website intercept recruitment, member referrals, targeted email lists, gaming sites, customer loyalty web portals, permission-based networks, and social media. Qualtrics Panel members' names, addresses, and dates of birth are typically validated via third party-verification. For our survey, Panel members received an invitation with a hyperlink to the NWS. Qualtrics compensated respondents in various ways, such as airline miles and gift cards, that respondents agreed to when they joined the Panel. The average time for survey completion was 22.9 minutes.

The sampling frame was adults ages 18-64 residing in the U.S. We provided Qualtrics with quotas for age, race, sex, and rural-urban continuum based on the American Community Survey estimates for 2015-19 and the USDA Economic Research Service's (ERS) rural-urban continuum codes (RUCCs). We intentionally over-sampled rural residents to achieve large enough sample sizes to conduct robust within-rural analysis. Accordingly, Qualtrics constructed post-stratification weights to align the sample with the U.S. population distribution. Given differential survey response by educational attainment, the post-stratification weight also incorporated education. Appendix Table A1 shows that, when weighted, the NWS sample is representative of the U.S. population ages 18-64 by age, sex, race/ethnicity, education, marital status, presence of children in the household, and rural-urban continuum. Means across several county-level demographic and socioeconomic characteristics from the 2015-2019 American 
Community Survey are also comparable between counties represented by NWS respondents and U.S. counties overall (see Appendix Table A2).

The overall response rate (number of surveys completed vs. number of surveys invited) was $5 \%$, which is in line with the rate of $7.3 \%$ on the Census Household Pulse Survey in the same time period and higher than the Census Household Pulse response rates of $<4 \%$ in its first 3 weeks of collection (U.S. Census Bureau 2021). However, the traditional response rate is not a useful measure for opt-in online panels because they use passive recruitment (e.g., invitation could be embedded in a longer email, repeated invitations are not sent), and it does not account for whether the email was opened or sent to junk folders. Instead, the completion rate is a better response measure. Of the 11,580 panel members who accessed the NWS landing page and reviewed the informed consent, 4,014 met the age eligibility criteria and data quality threshold, ${ }^{1}$ providing a strong completion rate of $40.4 \%$. We also compared prevalence rates on several health conditions and COVID-19 NWS items to similarly-worded items from other national surveys, including the Census Household Pulse Survey waves that were conducted during the same weeks as the NWS. We found prevalence rates to be comparable (see Appendix Table A3).

Data were missing on $6 \%$ of cases $(\mathrm{N}=242)$ for the variables included in this analysis. Most of the missing responses $(\mathrm{N}=161)$ were on household income. Rather than exclude these respondents, I created a dummy variable for missing income. Accordingly, the final analytic sample size was 3,933 .

\section{Outcomes}

The outcomes are several items related to COVID-19 infection and exposure experiences and how COVID-19 impacted respondents along domains of mental and physical health, 
relationships with friends and family, employment, and financial hardship. A benefit is that the "causal attribution" of COVID-19 on people's lives is supplied by the respondents themselves. The survey was conducted approximately one year after COVID-19 took root in the U.S. Therefore, the information is timely and captures the cumulative toll of the pandemic in its first year. Nonetheless, because we do not have baseline measures on wellbeing outcomes, the relationships cannot be concluded to be causal.

General COVID-19 impact is measured with the item: "All things considered, what impact would you say COVID-19 has had on your life?" with the response options of: 'COVID19 has had a negative impact on my life,' 'COVID-19 has had a positive impact on my life,' and 'COVID-19 has not really affected my life one way or the other.' This was the first item asked in the COVID-19 module, reducing the probability that respondents' answers on this item were influenced by subsequent items about specific COVID-19 experiences. For analysis, I dichotomized this item so that ' 1 '=negative impact and ' 0 '=positive or no impact.

Experiences with COVID-19 exposure and infection are captured with eight dichotomous items that were prefaced with "Which of the following experiences of COVID-19 applied to you?": received a coronavirus test (calculated by combining responses on two items that asked about whether they received a coronavirus test and it came back positive or negative); tested positive for coronavirus; hospitalized due to coronavirus; close family member hospitalized due to coronavirus; lived with someone who tested positive; close friend or family member outside of household tested positive; anyone in household (including self) had to quarantine due to exposure; and family member or friend died from coronavirus.

Physical and mental health impacts are captured with six items. Global physical health impact is captured with the item "Overall, please rate how the COVID-19 pandemic has affected 
the following aspects of your life: physical health", with a 5-point response scale of 'substantially improved' to 'substantially worsened'. An item with the same wording captures global mental health impact. I dichotomized each of these items so that ' 1 '=somewhat or substantially worsened and ' 0 '=no change or somewhat or substantially improved. Health care access impact is measured with the dichotomous item: "Was there a time in the past 12 months when you needed to see a doctor but could not: because of COVID-19?" Mental health treatment need is measured with the dichotomous item: "Which of the following experiences did you have as a result of COVID-19 related closures and/or other social distancing protocols?: I sought treatment for anxiety or depression.” Anxiety and depression were captured in the survey with the PHQ-4. Depression is measured with the two items: "During the past two weeks, how often have you been bothered by: having little interest or pleasure in doing things; and feeling down, depressed, or hopeless." Anxiety is measured with the two items: "During the past two weeks, how often have you been bothered by: feeling nervous, anxious, or on edge; and not being able to control worrying." Responses are measured on a 4-item scale from 'not at all' to 'nearly every day'. I classified respondents as experiencing anxiety or depression based on optimal cutpoint criteria (scores $\geq 3$ on each combined 2-item scale) (Kroenke et al. 2007). Although these items did not ask explicitly about COVID-19 impacts on anxiety and depression, the NWS survey was administered while the U.S. was still in the midst of the pandemic (Feb/March 2021), and the items asked about experiences in the past two weeks. The Census Household Pulse survey also regularly includes these items to surveil anxiety and depression prevalence throughout the pandemic.

Social impacts are captured with two items: "Overall, please rate how the COVID-19 pandemic has affected the following aspects of your life.": 'relationship with immediate family'; 
'relationship with friends', with a 5-point response scale of 'substantially improved' to 'substantially worsened'. I dichotomized both items so that respondents who reported somewhat or substantially worsened are coded ' 1 ' and all others are coded as ' 0 ' for each item.

Employment impacts are captured with eight dichotomous items prefaced with the question: "Which of the following experiences did you have as a result of COVID-19 related closures and/or other social distancing protocols?": lost job; experienced a reduction in pay; was considered an essential worker; worked remotely; worked fewer hours than normal; worked more hours than normal; worked remotely while taking care of own children who could not attend daycare or school; unable to work because children could not attend daycare or school. I restricted analysis for the last two items to respondents who indicated there were children under age 18 living in the household $(\mathrm{N}=1,495)$.

Finally, financial impacts are captured with five dichotomous items prefaced with the question: "Which of the following experiences did you have as a result of COVID-19 related closures and/or other social distancing protocols?": late paying rent or mortgage; late paying other bills; could not afford groceries or other necessities; paid bills of friend or family members; and got a loan from family or friend. In addition, I include: "Overall, please rate how the COVID-19 pandemic has affected the following aspects of your life - financial situation.” I recoded the original 5-point response scale so that those who responded with substantially or somewhat worsened were coded as ' 1 ' and everyone else was coded as ' 0 '.

\section{Metropolitan Status}

The NWS includes respondent FIPS codes, enabling me to identify the metropolitan status of county of residence. I classified metropolitan status with four categories based on the 
USDA ERS rural-urban continuum codes (RUCCs): large urban (RUCC 1, counties in metro areas of 1 million population or more); medium/small urban (RUCCs 2 and 3, counties in metro areas of less than 1 million population); rural adjacent to metro (RUCCs 4, 6, and 8, nonmetro counties adjacent to metro areas); and remote rural RUCCs 5, 7, and 9, nonmetro counties not adjacent to metro areas). Sample sizes do not permit further disaggregation.

\section{Covariates}

Regression models control for sex, race/ethnicity, marital status, number of adults and children under age 18 in the household, household income in 2019, educational attainment, home ownership status, whether the respondent moved to the county in the past 12 months, political party affiliation, and 2020 Presidential vote.

\section{Analysis}

I first present prevalence rates for each outcome for the sample overall and by metro status. I then present results from a series of 3-level multilevel logistic regression models with random intercepts for counties and states to account for the geographic clustering of respondents. In lieu of random effects for states, I attempted to include state fixed effects (dummy variables). Several of the models did not converge, indicating that the sample sizes do not permit the inclusion of state dummy variables. Moreover, although there was significant state-level clustering for some of the outcome variables (requiring a state-level random intercept in the model), it was not the case for all outcomes. For the sake of model consistency, I present findings only for the 3-level models with random state-level intercepts. Accordingly, the models for some outcomes may be over-specified, and the findings related to metro status differences 
should be considered as conservative estimates; the standard errors are larger than they would be without the inclusion of state-level random intercepts.

The models predict metro status differences in the odds of each outcome. Large urban is the reference category. I first present results from unadjusted models that account only for the clustering of respondents within counties and states. The second set of models include all covariates listed above. Given the large number of outcomes considered, I do not show coefficients for the covariates, but they are available upon request. All models are weighted with the final post-stratification weight created by Qualtrics to make the sample nationally representative by age, sex, race/ethnicity, educational attainment, and rural-urban continuum.

\section{Results}

Prevalence rates for all outcomes for the sample overall are presented in Table 1. Nearly $58 \%$ of respondents reported that COVID-19 has had a negative impact on their lives. Over a third of respondents met the criteria for depression (33.3\%) and anxiety (34.2\%) in the past two weeks and reported that their mental health (37.9\%) and financial situation (34.6\%) were worse due to COVID-19. Nearly $30 \%$ reported that their physical health was worse, and $18 \%$ reported seeking treatment for anxiety or depression due to COVID-19.

$<$ Table 1 here>

Figures 1-6 show metro status differences in unadjusted prevalence rates for each outcome. T-tests identify whether there are statistically significant differences compared to the reference category (large urban). Of the 31 outcomes, there are statistically significant 
differences in 24. There are not significant differences in the global COVID-19 impact item (Figure 1).

In terms of experiences with COVID-19 exposure and infection (Figure 2), residents of large urban counties are significantly more likely than residents of the other metro status types to have received a coronavirus test. For example, whereas $42.3 \%$ or large urban respondents reported receiving a test, only $34.8 \%$ of remote rural respondents reported being tested. Residents of rural metro-adjacent counties are significantly more likely than residents of large urban counties to have had a close family member hospitalized due to coronavirus $(13.3 \%$ vs. 9.0\%); have a close friend or family member outside of the household test positive (38.2\% vs. 28.2\%); have had anyone in the household had to quarantine due to exposure (18.9\% vs. $13.4 \%$ ), and to have a friend or family member die due to coronavirus (15.2\% vs. 12.0\%). Residents of remote rural counties are also more likely than those in large urban counties to have a friend or family member outside of the household test positive (34.4\%), and residents of medium/small urban counties are more likely than those in large urban counties to have had a friend or family member die from coronavirus $(14.9 \%)$.

Residents of rural counties also experienced worse physical and mental health impacts (Figure 3). Respondents in rural counties adjacent to metro areas were more likely than those in large urban counites to report that their mental health worsened due to COVID-19 (40.4\% vs. $36.1 \%)$ and that they sought treatment for anxiety or depression $(23.6 \%$ vs. $17.1 \%)$. They were also more likely to meet the criteria for depression and anxiety, as were residents of small/medium metro counties and remote rural counties.

In terms of social impacts (Figure 4), residents of rural counties adjacent to metro areas were significantly more likely than their large urban peers to report that their relationship with 
their immediate family worsened $(25.9 \%$ vs. $19.4 \%)$. The difference for relationship with friends was not statistically significant.

Conversely, rural residents performed better on several employment outcomes (Figure 5). Residents of large urban counties were the most likely to report losing a job (16.2\%), experiencing a reduction in pay $(21.7 \%)$, working remotely $(33.7 \%)$, working both fewer $(27.1 \%)$ and more $(17.3 \%)$ hours than normal, and working remotely while taking care of children who could not attend day care or school (31.3\%).

Despite their comparative advantage with employment outcomes, residents of rural counties adjacent to metro areas reported the worst financial impacts (Figure 6). They were the most likely to report being late paying the rent or mortgage, late paying other bills, not being able to afford groceries or other necessities, getting a loan from a friend or family member, and that their financial situation worsened during COVID-19. For example, whereas $33.1 \%$ of large urban residents reported that their financial situation worsened, $40.2 \%$ of rural residents adjacent to metro areas reported that their financial situation worsened. Residents of small/medium urban and remote rural counties were also more likely than those in large urban counties to report being late paying other bills and not being able to afford groceries or other necessities.

\section{$<$ Figures 1-6 here>}

Odds ratios from unadjusted multilevel logistic regression models are presented in Table 2. Although differences in some of the outcomes are no longer statistically significant after accounting for respondent clustering within counties and states, the direction of the differences remain the same. Residents of rural counties adjacent to metro areas generally have higher odds 
of reporting adverse outcomes. Residents of remote rural counties were also more likely than those in large urban counties to report several of the negative health and financial outcomes, but few differences rose to the level of statistical significance.

$<$ Table 2 here>

Table 3 presents odds ratios from models adjusted for covariates. The inclusion of covariates eliminated the statistical significance for some, though not most, significant differences between residents of rural counties adjacent to metro areas and those in large urban counties. Net of controls, residents of rural counties adjacent to metro areas were more likely than their large urban peers to report testing positive for coronavirus ( $\mathrm{OR}=1.56$ [1.03 to 2.39]) and living with someone who tested positive ( $\mathrm{OR}=1.95$ [1.17 to 3.21]), having a close friend or family member hospitalized ( $\mathrm{OR}=1.64$ [1.11 to 2.52$]$ ), having a close friend or family member outside of the household test positive ( $\mathrm{OR}=1.32$ [1.00 to 1.73]), seeking treatment for anxiety or depression due to COVID-19 (OR=1.41 [1.03 to 1.92]), meeting the threshold for anxiety $(\mathrm{OR}=1.27[0.97$ to 1.67$])$, reporting worsened relationships with friends $(\mathrm{OR}=1.30$ [0.96 to 1.76]) and immediate family ( $\mathrm{OR}=1.30$ [0.98 to 1.73]), working fewer hours than normal $(\mathrm{OR}=1.29,[0.96$ to 1.72$])$, being late paying rent or mortgage $(\mathrm{OF}=1.55$ [1.12 to 2.15$])$ and other bills ( $\mathrm{OR}=1.61[1.20$ to 2.16$])$, not being able to afford groceries or other necessities ( $\mathrm{OR}=1.57$ [1.14 to 2.15]), and getting a loan from family or friends ( $\mathrm{OR}=1.65$ [1.16 to 2.36]). Most outcomes for remote rural residents were also worse compared to large urban residents (with the exception of employment impacts, which were worse among large urban residents), but differences were not statistically significant net of covariates. 
$<$ Table 3 here>

\section{Discussion and Conclusions}

The consequences of COVID-19 go beyond its direct impact on loss of life. Using data from a timely and novel survey of working-age adults (ages 18-64) conducted in February and March 2021 (the National Wellbeing Survey) (Monnat and Rhubart 2021), I found widespread adverse secondary impacts from the COVID-19 pandemic, including to mental health, social relationships, and financial wellbeing. Well over half of respondents reported that the pandemic had a negative impact on their lives, and non-negligible shares met the criteria for depression and anxiety and reported that their mental health, physical health, and financial situation were worse due to COVID-19.

As with COVID-19 mortality itself (Cheng et al. 2020; Cromartie et al. 2020; Sun et al. 2021), the mental health, social, and financial consequences of the pandemic have not been distributed equally across geography. My findings show that residents of rural counties that are adjacent to metro areas were more likely than their large urban peers to report worse outcomes on multiple measures, including testing positive for coronavirus, living with someone who tested positive, having a close friend or family member outside of the household test positive, having a close friend or family member hospitalized, seeking treatment for anxiety or depression, meeting the threshold for anxiety, and reporting that their relationships with friends or immediate family worsened. Consistent with previous research (Brooks et al. 2021), I found that residents of large urban counties were more likely to report losing a job, experiencing a reduction in pay, and working remotely. However, those differences were no longer statistically significant after 
introducing covariates. Despite their comparative advantage with employment outcomes, residents of rural counties adjacent to metro areas also reported the worst financial impacts, including being late paying rent, mortgage, and other bills, not being able to afford groceries or other necessities, and getting a loan from family or friends. Residents of remote rural counties also reported worse outcomes than large urban residents on several indicators, but differences were no longer statistically significant after introducing covariates.

Although it was beyond the scope of this study to explore explanations for these differences, it is possible that rural residents were at greater risk of adverse psychological and financial outcomes due to their disadvantaged socioeconomic profiles that make them more vulnerable to economic shocks. Different workplace conditions and/or prevention behaviors (e.g., mask wearing, avoiding gatherings) may explain why residents of rural counties adjacent to metro areas reported the most personal experiences with COVID-19 infection (testing positive, having friends/family who tested positive, friend/family member hospitalized). Explaining these differences is a target for future research.

The findings from this study should be considered in light of some limitations. First, the data are cross-sectional and capture one point in time during the pandemic (approximately one year after the virus began to spread in the U.S.). Although these analyses relied on questions where respondents place the causal attribution for outcomes on the pandemic, causality should not be presumed given that we do not have baseline measures of the outcomes and cannot assess how they changed from before the pandemic. Second, the sampling frame for the NWS relies on a non-probability opt-in survey panel, which raises concerns about non-coverage and differential non-response biases. Although the sample is demographically representative, it may not be representative on COVID-19 impacts. For example, those who are the most negatively impacted 
by COVID-19 may be least likely to complete surveys. Conclusions drawn from research on consistency of findings between non-probability and probability samples is mixed. While some raise doubts about the validity of non-probability samples (Yeager et al. 2011; Loosveldt and Sonck 2008; Malhotra and Krosnick 2007), others find that even highly-selective samples yield strong accuracy on demographics (Kalimeri et al. 2020) and risk factors for mortality (Batty et al. 2020), and for most questions, the differences between probability and non-probability samples are small (Goel et al. 2017). I found strong comparability between several univariate estimates from the NWS and those from other surveys such as the National Health Interview Survey, Census Household Pulse, and American Family Survey, lending credibility to the generalizability of the NWS. However, the NWS respondents lean politically liberal, ${ }^{2}$ which may bias the findings. Third, sample sizes did not permit the inclusion of state fixed effects. Results may be influenced by unobserved state-level variation in COVID-19 mitigation policies, politics, and other factors that may influence COVID-19 experiences and impacts. However, explaining the observed metro status differences was beyond the scope of this study, and state-level policies may act as mediators between metro status and COVID-19 experiences and impacts. Future research should consider the role of state policies and other potential mediators on rural-urban continuum differences in various immediate and longer-term COVID-19 outcomes. Finally, just as there is variation between counties, there is also important variation within counties, with certain population pockets within each metro status category at greater risk of poor outcomes than others, including racial/ethnic minority and low SES groups. The results presented here should not be presumed to apply equally to all population subgroups within a particular metropolitan status category.

Despite these limitations, this study is the first to examine rural-urban continuum 
differences in secondary impacts from the COVID-19 pandemic using a national sample of working-age adults - a population that has been hit especially hard by the pandemic's economic and mental health consequences (Gassman-Pines et al. 2020; Glei 2021; Horowitz et al. 2021; Kesler and Bash 2021; Montenovo et al. 2020). Findings reinforce the fact that rural areas are not homogenous and that some experienced worse outcomes than others during the COVID-19 pandemic. Recovery policies must consider geographic variation in COVID-19 vulnerability and impacts.

As with the Great Recession (Forbes and Krueger 2019), the economic, social, and psychological sequalae of COVID-19 and its related policies may reverberate for years given its broad and sustained disruption to the U.S.'s economic, social, and health care infrastructures. COVID-19 and its post-pandemic contexts may precipitate major economic, social, cultural, and institutional changes that will have implications for physical, psychological, and financial health well into the future. Although the COVID-19 unemployment rate was higher than in previous recessions (Congressional Research Service 2021), several federal and state mitigation policies, such as extended unemployment benefits and eviction moratoria, potentially buffered some individuals, families, and communities from short-term material and psychological distress. However, many states are phasing out these policies, which may leave some people less financially secure than at the height of the pandemic. As a result, material wellbeing may decline and psychological distress may increase in coming months. Also, as eviction moratoria are phased out, more people could be left homeless as they are unable to make overdue rent payments. Those who contracted COVID-19 or delayed medical care may have new health conditions with which to contend. It is also possible that COVID-19 may have prompted an "existential shift" for some individuals, who made adaptations that are beneficial to 
psychological wellbeing (e.g., more fulfilling employment, more time with friends and family). Many businesses closed, perhaps permanently. As a result, people may not return to their same jobs or even their same industries. Some may retire earlier than expected (Bond et al. 2021). Businesses may adopt remote, hybrid, or other flexible work arrangements, and labor shortages may prompt wage increases that benefit workers. To the extent that these changes vary geographically, we should also expect to see geographic differences in physical and mental health outcomes and financial wellbeing. Researchers should continue to explore geographic differences in these longer-term outcomes, including along the rural-urban continuum and between different types of rural communities. 


\section{References}

Adolph, Christopher, Kenya Amano, Bree Bang-Jensen, Nancy Fullman, and John Wilkerson. 2021. Pandemic politics: timing state-level social distancing responses to COVID-19. Journal of Health Politics, Policy and Law 46 (2): 211-33.

Batty, G. David, Catharine R. Gale, Mika Kivimäki, Ian J. Deary, and Steven Bell. 2020 Comparison of risk factor associations in UK Biobank against representative, general population based studies with conventional response rates: prospective cohort study and individual participant meta-analysis. BMJ 368: $\mathrm{m} 131$.

Board of Governors of the Federal Reserve System. 2020. Economic well-being of U.S. households in 2020. Available from https://www.federalreserve.gov/publications/2021economic-well-being-of-us-households-in-2020-executive-summary.htm (accessed 30 May 2021)

Bond, Tyler, Dan Doonan, and Kelly Kenneally. 2021. Retirement insecurity 2021: Americans views of retirement. National Institute on Retirement Security. Available from https://www.nirsonline.org/wp-content/uploads/2021/02/FINAL-Retirement-Insecurity2021-.pdf (accessed 7 July 2021).

Brodeur, Abel, Andrew E. Clark, Sarah Fleche, and Nattavudh Powdthavee. 2021. COVID-19, lockdowns and well-being: evidence from Google Trends. Journal of Public Economics 193: 104346.

Brooks, Matthew M., J. Tom Mueller, and Brian C. Thiede. 2021. Rural-urban differences in the labor-force impacts of COVID-19 in the United States. Socius 7: 1-12.

Calbi, Marta, Nunzio Langiulli, Francesca Ferroni, Martina Montalti, Anna Kolesnikov, Vittorio Gallese, and Maria Alessandra Umilta. 2021. The consequences of COVID-19 on social interactions: an online study on face covering. Scientific Reports 11 (2601).

Callaghan, Timothy, Jennifer A., Lueck, Kristin L., Trujillo, and Alva O. Ferdinand. 2021. Rural and urban differences in COVID-19 prevention behaviors. The Journal of Rural Health 37 (2): 287-95.

Carr, Patrick J. and Maria J. Kefalas. 2009. Hollowing out the middle: the rural brain drain and what It means for America. Boston, MA: Beacon Press.

Cecil G. Sheps Center for Health Services Research. 2021. Rural hospital closures. Available from https://www.shepscenter.unc.edu/programs-projects/rural-health/rural-hospitalclosures/ (accessed 18 June 2021).

Cheng, Kent Jason G., Yue Sun, and Shannon M. Monnat. 2020. COVID-19 death rates are higher in rural counties with larger shares of blacks and hispanics. The Journal of Rural Health 36 (4): 602-8.

Cho, Seung Jin, Jun Yeong Lee, and John V. Winters. 2020. Employment impacts of the Covid19 pandemic across metropolitan status and size. IZA Discussion Paper No. 13468. Available from https://ssrn.com/abstract=3648808 (accessed 7 July 2021).

Cohen, Philip N. 2020. The COVID-19 epidemic in rural U.S. counties. European Journal of Environment and Public Health 4 (2): em0050.

Collins, Caitlyn, Liana Christin Landivar, Leah Ruppanner, and William J. Scarborough. 2021. COVID-19 and the gender gap in work hours. Gender, Work \& Organization 28 (S1): 101-112.

Congressional Research Service. 2021. Unemployment rates during the COVID-19 pandemic. R46554. Available from https://fas.org/sgp/crs/misc/R46554.pdf (accessed 2 July 2021). 
Cromartie, John, Elizabeth A. Dobis, Thomas P. Krumel, David McGranahan, and John Pender. 2020. Rural America at a glance, 2020 edition. Available from https://www.ers.usda.gov/publications/pub-details/?pubid=100088 (accessed 21 June 2021).

Czeisler, Mark É., Rashon I. Lane, Emiko Petrosky, Joshua F. Wiley Aleta Christensen, Rashid Njai, Matthew D. Weaver, Rebecca Robbins, Elise R. Facer-Childs, Laura K. Barger, Charles A. Czeisler, Mark E. Howard, and Shantha M.W. Rajaratnam. 2020a. Mental health, substance use, and suicidal ideation during the COVID-19 pandemic-United States, June 24-30, 2020. Morbidity and Mortal Weekly Report 69: 1049-1057.

Czeisler, Mark É, Kristy Marynak, Kristie E.N. Clarke, Zainab Salah, Iju Shakya, JoAnn M. Thierry, Nida Ali, Hannah McMillan, Joshua F. Wiley, Matthew D. Weaver, Charles A. Czeisler, Shantha M.W. Rajaratnam, and Mark E. Howard. 2020b. Delay or avoidance of medical care because of COVID-19-related concerns - United States, June 2020. Morbidity and Mortal Weekly Report 69: 1250-1257.

Dias, Felipe A. 2021. The racial gap in employment and layoffs during COVID-19 in the United States: a visualization. Socius doi:10.1177/2378023120988397.

Forbes, Miriam K. and Robert F. Krueger. 2019. The Great Recession and mental health in the United States. Clinical Psychological Science 7 (5): 900-913.

Gassman-Pines, Anna, Elizabeth O. Ananat, and John Fitz-Henley. 2020. COVID-19 and parentchild psychological well-being. Pediatrics 146 (4): e2020007294.

Glei, Dana A. 2021. The U.S. midlife mortality crisis continues: increased death rates from causes other than COVID-19 during 2020. medRxiv [Preprint]. Available from https://pubmed.ncbi.nlm.nih.gov/34031664/ (accessed 28 July 2021).

Goel, Sharad, Adam Obeng, and David Rothschild. 2017. Non-representative surveys: fast, cheap, but are they accurate? Working Paper. Available from https://adamobeng.com/download/FastCheapAccurate.pdf) (accessed 7 July 2021).

Gong, Gordon, Scott G. Phillips, Catherine Hudson, Debra Curti, and Billy U. Phillips. 2019. Higher US rural mortality rates linked to socioeconomic status, physician shortages, and lack of health insurance. Health Affairs 38 (12): 2003-10.

Gross, Betheny and Alice Opalka. 2020. Too many schools leave learning to chance during the pandemic. Center on Reinventing Public Education. Available from https://www.crpe.org/publications/too-many-schools-leave-learning-chance-duringpandemic (accessed 7 July 2021).

Haischer, Michael H., Rachel Beilfuss, Meggie R. Hart, Lauren Opielinski, David Wrucke, Gretchen Zirgaitis, Toni D. Uhrich, and Sandra K. Hunter. 2020. Who is wearing a mask? Gender-, age-, and location-related differences during the COVID-19 pandemic. PLOS ONE 15 (10): e0240785.

Hays, Ron D., Honghu Liu, and Arie Kapteyn. 2015. Use of internet panels to conduct surveys. Behavior Research Methods 47 (3): 685-90.

Hooks, Gregory and Wendy Sawyer. 2020. Mass incarceration, COVID-19, and community spread. Prison Policy Initiative. Available at https://www.prisonpolicy.org/reports/covidspread.html (accessed 7 July 2021).

Horowitz, Juliana M., Anna Brown, and Rachel Minkin. 2021. A year into the pandemic, longterm financial impact weighs heavily on many Americans. Pew Research Center. Available from https://www.pewresearch.org/social-trends/2021/03/05/a-year-into-the- 
pandemic-long-term-financial-impact-weighs-heavily-on-many-americans/ (accessed 2 July 2021)

Huang, Qian, Sarah Jackson, Sahar Derakhshan, Logan Lee, Erika Pham, Amber Jackson, and Susan L. Cutter. 2021. Urban-rural differences in COVID-19 exposures and outcomes in the South: a preliminary analysis of South Carolina. PLOS ONE 16 (2): e0246548.

Jensen, Leif and Tim Slack. 2003. Underemployment in America: measurement and evidence. American Journal of Community Psychology 32 (1-2): 21-31.

Kaiser Family Foundation. 2021. Does the public want to get a COVID-19 vaccine? when? KFF COVID-19 Vaccine Monitor Dashboard. Available from https://www.kff.org/coronavirus-covid-19/dashboard/kff-covid-19-vaccine-monitordashboard/ (accessed 18 June 2021).

Kalimeri, Kyriaki, Mariano G. Beiro, Andrea Bonanomi, Alessandro Rosina, and Ciro Cattuto. 2020. Traditional versus Facebook-based surveys: evaluation of biases in self-reported demographic and psychometric information. Demographic Research 42 (5): 133-148.

Kesler, Christel and Sarah Bash. 2021. A growing educational divide in the COVID-19 economy is especially pronounced among parents. Socius doi: $10.1177 / 2378023120979804$.

Killgore, William D.S., Sara A. Cloonan, Emily C. Taylor, Matthew C. Allbright, and Natalie S. Dailey. 2020. Trends in suicidal ideation over the first three months of COVID-19 lockdowns. Psychiatry Research 293: 113390.

Kovacs, Balazs, Nicholas Caplan, Samuel Grob, and Marissa King. 2021. Social networks and loneliness during the COVID-19 pandemic. Socius. doi:10.1177/2378023120985254.

Kroenke, Kurt, Robert L. Spitzer, Janet B.W. Williams, Patrick O. Monahan, and Bernd Lowe. 2007. Anxiety disorders in primary care: prevalence, impairment, comorbidity, and detection. Annals of Internal Medicine 146: 317-325.

Landivar, Liana C., Leah Ruppanner, William J. Scarborough, Caitlyn Collins. 2020. Early signs indicate that COVID-19 is exacerbating gender inequality in the labor force. Socius 6: 13.

Li, Jie, Daniel Q., Huang, Biyao Zou, Hongli Yang, Wan Zi Hui, Fajuan Rui, Natasha Tang Sook Yee, Chuanli Liu, Sanjna Nilesh Nerurkar, Justin Chua Ying Kai, Margaret Li Peng Teng, Xiaohe Li, Hua Zeng, John A Borghi, Linda Henry, Ramsey Cheung, and Mindie H Nguyen. 2021. Epidemiology of COVID-19: a systematic review and meta-analysis of clinical characteristics, risk factors, and outcomes. Journal of Medical Virology 93 (3): 1449-58.

Lin, Ge, Tonglin Zhang, Ying Zhang, and Quanyi Wang. 2021. Statewide stay-at-home directives on the spread of COVID-19 in metropolitan and nonmetropolitan counties in the United States. The Journal of Rural Health 37: 222-223.

Loosveldt, Geert and Nathalie Sonck. 2008. An evaluation of the weighting procedures for an online access panel survey. Survey Research Methods 2 (2): 93-105.

Malhotra, Neil and Jon A. Krosnick. 2007. The effect of survey mode and sampling on inferences about political attitudes and behavior: comparing the 2000 and 2004 ANES to internet surveys with nonprobability samples. Political Analysis 15: 286-323.

McPhee, Matthew D., Matthew T. Keough, Samantha Rundle, Laura M. Heath, Jeffrey D. Wardell, and Christian S. Hendershot. 2020. Depression, environmental reward, coping motives and alcohol consumption during the COVID-19 pandemic. Front Psychiatry 11: 574676. 
Meit, Michael, Alan Knudson, Tess Gilbert, Amanda Tzy-Chyi, Erin Tanenbaum, Elizabeth Ormson, Shannon TenBroeck, Alycia Bayne, and Shena Popat. 2014. The 2014 update of the rural-urban chartbook. NORC Walsh Center for Rural Health Analysis. Available from https:// ruralhealth.und.edu/projects/healthreform-

policy-research-center/pdf/ 2014-rural-urban-chartbook-update.pdf (accessed 2 July 2021). Monnat, Shannon M. 2020. Why coronavirus could hit rural areas harder. Lerner Center for Public Health Promotion. Available from https://lernercenter.syr.edu/2020/03/24/whycoronavirus-could-hit-rural-areas-harder/ (accessed 9 November 2020).

Monnat, Shannon M. and Camille Beeler Pickett. 2011. Rural/urban differences in self-rated health: examining the roles of county size and metropolitan adjacency. Health \& Place 17 (1): 311-319.

Monnat, Shannon M. and Danielle C. Rhubart. 2021. National Wellbeing Survey. Lerner Center for Public Health Promotion. Syracuse University.

Montenovo, Laura, Xuan Jiang, Felipe Rojas, Ian M. Schmutte, Kosali I. Simon, Bruce A. Weinberg, and Coady Wing. 2020. Determinants of disparities in COVID-19 job losses. NBER Working Paper 27132. Available at https://www.nber.org/papers/w27132 (accessed 28 July 2021).

Mueller, J. Tom, Kathryn McConnell, Paul Berne Burow, Katie, Pofahl, Alexis A. Merdjanoff, and Justin Farrell. 2021. Impacts of the COVID-19 pandemic on rural America. Proceedings of the National Academy of Sciences 118 (1): 2019378118.

National Center for Health Statistics. 2019. National Health Interview Survey tables of summary health statistics. Available at https://www.cdc.gov/nchs/nhis/shs/tables.htm. (accessed 2 July 2021).

Pender, John. 2021. The COVID-19 pandemic and rural America. USDA Economic Research Service. Available from https://www.ers.usda.gov/covid-19/rural-america/ (accessed 2 July 2021).

Perry, Brea L., Brian Aronson, and Bernice A. Pescosolido. 2020. Pandemic precarity: COVID19 is exposing and exacerbating inequalities in the American heartland. Proceedings of the National Academy of Sciences 118 (8): e2020685118.

Peters, David. 2020. Community susceptibility and resiliency to COVID-19 across the ruralurban continuum in the United States. The Journal of Rural Health 36 (3): 446-456.

Philpot, Lindsey M., Priya Ramar, Daniel L. Roellinger, Barbara A. Barry, Pravesh Sharma, and Jon O. Ebbert. 2021. Changes in social relationships during an initial "stay-at-home" phase of the COVID-19 pandemic: a longitudinal survey study in the U.S. Social Science \& Medicine 274: 113779.

Slack, Tim, Brian C. Thiede, and Leif Jensen. 2020. Race, residence, and underemployment: fifty years in comparative perspective, 1968-2017. Rural Sociology 85 (2): 275-315.

Souch, Jacob M. and Jeralynn S. Cossman. 2021. A commentary on rural-urban disparities in COVID-19 testing rates per 100,000 and risk factors. The Journal of Rural Health 37 (1): 188-190.

Sun, Yue, Kent Jason G. Cheng, and Shannon M. Monnat. 2021. Rural-urban and within-rural differences in COVID-19 mortality trends. SocArXiv. doi:10.31235/osf.io/jbhvs.

Taylor, Charles A., Christopher Boulos, and Douglas Almond. 2020. Livestock plants and COVID-19 transmission. Proceedings of the National Academy of Sciences 117 (5): 31706-31715. 
Thiede, Brian C., Daniel T. Lichter, and Tim Slack. 2018. Working, but poor: the good life in rural America? Journal of Rural Studies 59: 183-93.

Twenge, Jean M. and Thomas E. Joiner. 2020. US Census Bureau-assessed prevalence of anxiety and depressive symptoms in 2019 and during the 2020 COVID-19 pandemic. Depression and Anxiety 37 (10): 954-956.

U.S. Census Bureau. 2021. Household pulse survey technical documentation. Available from https://www.census.gov/programs-surveys/household-pulse-survey/technicaldocumentation.html (accessed 2 July 2021).

U.S. Centers for Disease Control and Prevention. 2020. People who are at higher riskfor severe illness. Available from https://www.cdc.gov/coronavirus/2019-ncov/need-extraprecautions/people-at-higher-risk.html (accessed 7 July 2021).

Yeager, David S., Jon A. Krosnick, LinChiat Chang, Harold S. Javitz, Matthew S. Levendusky, Alberto Simpser, and Rui Wang. 2011. Comparing the accuracy of RDD telephone surveys and internet surveys conducted with probability and non-probability samples. Public Opinion Quarterly 75 (4): 709-747.

Zhang, Charlie H. and Gary G. Schwartz. 2020. Spatial disparities in coronavirus incidence and mortality in the United States: an ecological analysis as of May 2020. The Journal of Rural Health 36 (3): 433-45. 


\begin{tabular}{lrc}
\hline & \multicolumn{2}{c}{ Analytic } \\
\hline All things considered COVID-19 has had negative impact on life & 57.6 & 3933 \\
COVID-19 Exposure and Infection Experiences & & \\
Received a coronavirus test & 39.2 & 3933 \\
Tested positive for coronavirus & 8.1 & 3933 \\
Hospitalized due to coronavirus & 1.3 & 3933 \\
Close family member hospitalized due to coronavirus & 9.2 & 3933 \\
Lived with someone who tested positive & 5.4 & 3933 \\
Close friend or family member outside of household tested positive & 30.3 & 3933 \\
Anyone in household had to quarantine due to exposure & 13.8 & 3933 \\
Family member or friend died from coronavirus & 13.2 & 3933 \\
Physical and Mental Health Impact & & \\
Physical health somewhat or substantially worse due to COVID-19 & 29.8 & 3933 \\
Mental health somewhat or substantially worse due to COVID-19 & 37.9 & 3933 \\
Couldn't see the doctor due to COVID-19 & 17.4 & 3933 \\
Sought treatment for anxiety or depression due to COVID-19 & 18.2 & 3933 \\
Depression (Scored 3 or higher on combined depression PHQ-2) & 33.3 & 3933 \\
Anxiety (Scored 3 or higher on combined anxiety PHQ-2) & 34.2 & 3933 \\
Impact on Social Relationships & & \\
\hline Relationship with immediate family somewhat or substantially worsened & 20.2 & 3933 \\
Relationship with friends somewhat or substantially worsened & 24.8 & 3933 \\
Employment Impacts & & \\
\hline Lost job & 14.7 & 3933 \\
Experienced a reduction in pay & 19.8 & 3933 \\
Was considered essential worker & 33.7 & 3933 \\
Worked remotely & 29.9 & 3933 \\
Worked fewer hours than normal & 25.4 & 3933 \\
Worked more hours than normal & 15.8 & 3933 \\
Worked remotely while taking care of own children who could not attend & 22.7 & 1595 \\
daycare or school* & 19.8 & 1595 \\
Unable to work because children could not attend daycare or school* & & \\
Financial Impact & 16.7 & 3933 \\
Late paying rent or mortgage & 23.9 & 3933 \\
Late paying other bills & 19.5 & 3933 \\
Could not afford groceries or other necessities & 15.3 & 3933 \\
Paid bills of friend or family member & 13.0 & 3933 \\
Got a loan from family or friend & 34.6 & 3933 \\
\hline Financial situation somewhat or substantially worsened & & \\
\hline
\end{tabular}

*Includes only respondents with children $<18$ in household. 
Figure 1. COVID-19 Has Had a Negative Impact on My Life

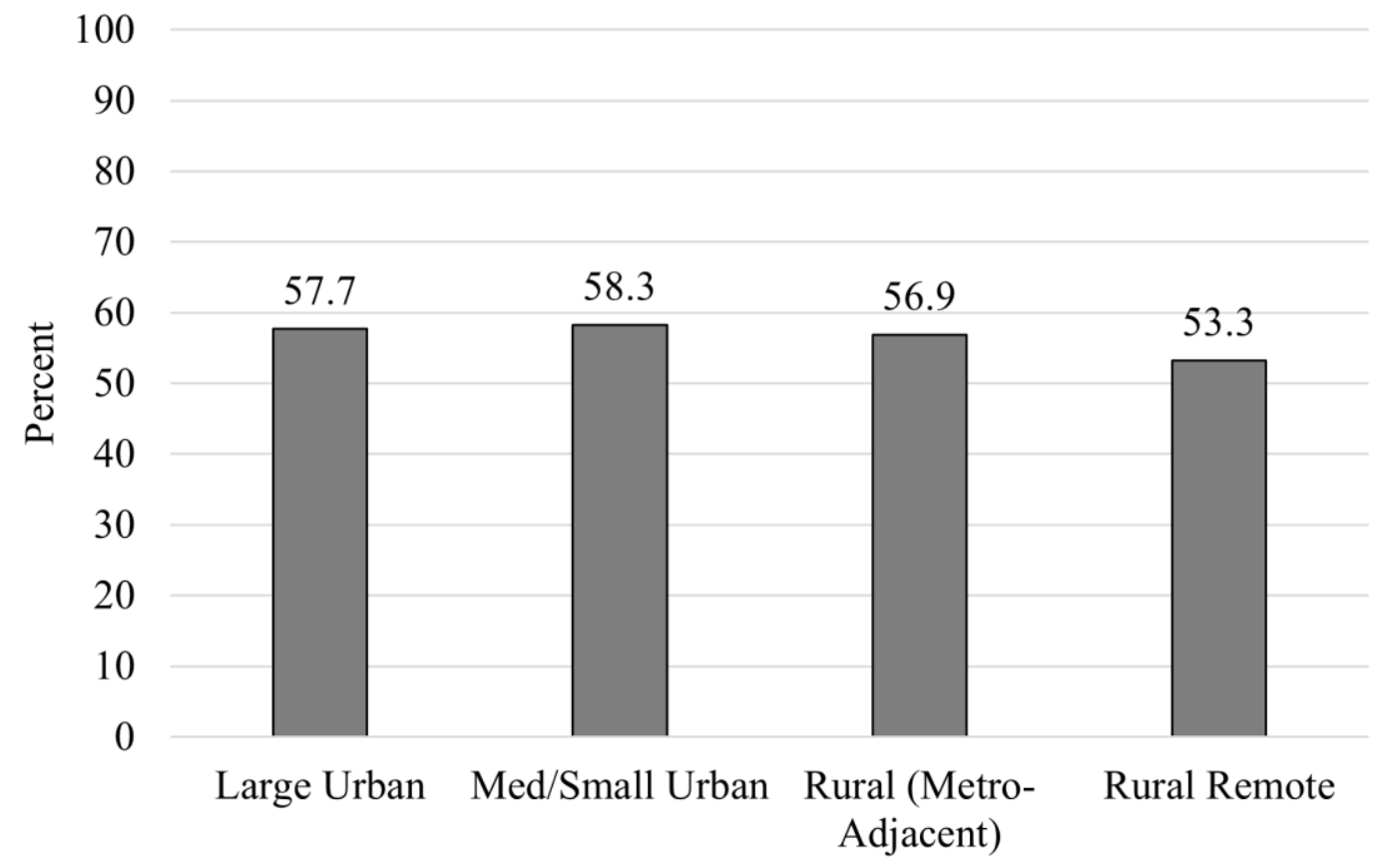

$\mathrm{N}=3,933$ adults ages 18-64; Large Urban=1,813; Medium/Small Urban=1007; Rural (MetroAdjacent $)=703$; Rural Remote $=410$; percentages are weighted; Differences are not statistically significant (large urban $=$ reference) . 
Figure 2. Experiences with COVID-19 Exposure and Infection

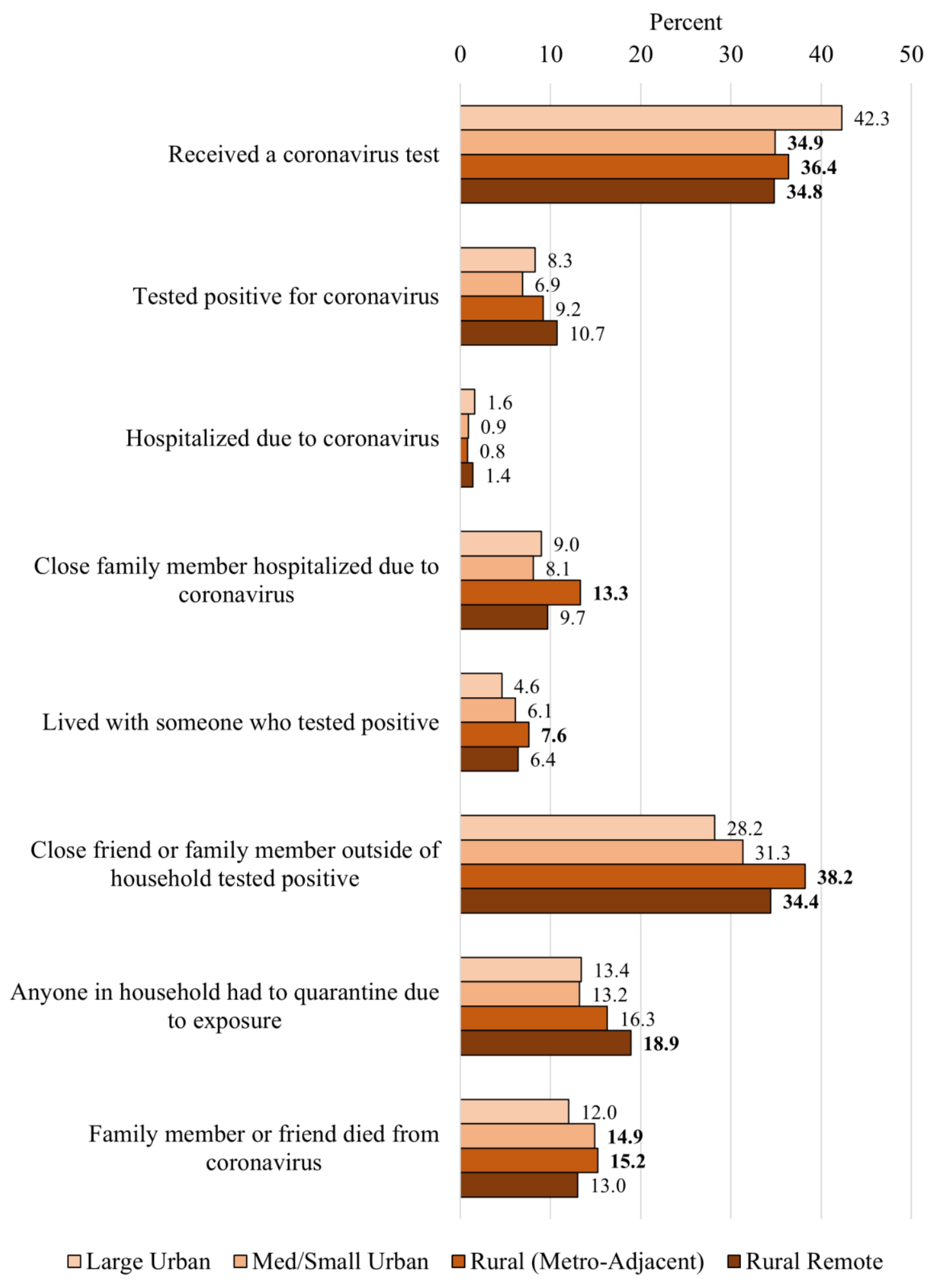

N=3,933 adults ages 18-64; Large Urban=1,813; Medium/Small Urban=1007; Rural (MetroAdjacent $)=703$; Rural Remote $=410$; percentages are weighted; bolded values indicate significant difference from large urban $(\mathrm{p}<0.05)$ 
Figure 3. Physical and Mental Health Impacts

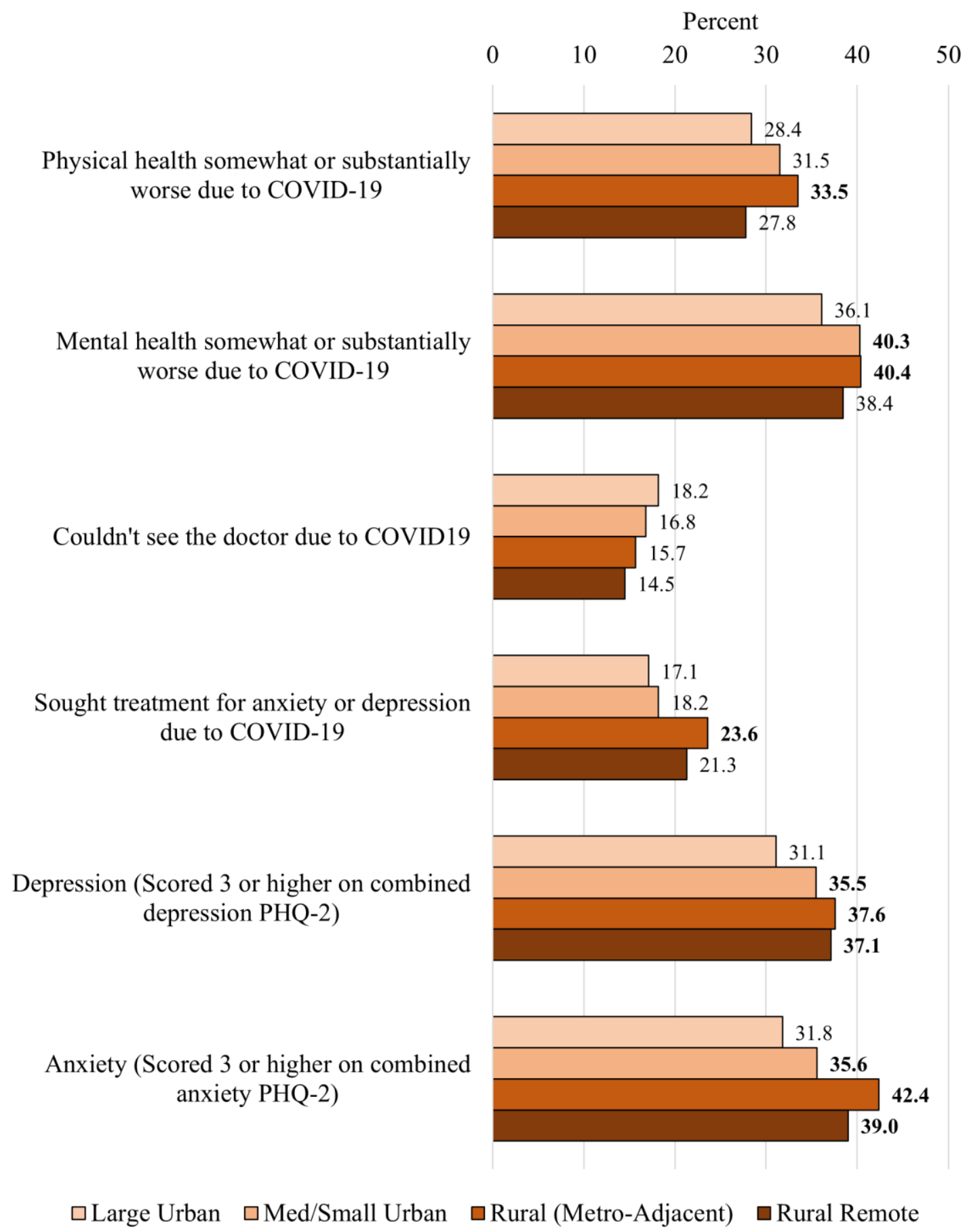

$\mathrm{N}=3,933$ adults ages 18-64; Large Urban=1,813; Medium/Small Urban=1007; Rural (MetroAdjacent $)=703$; Rural Remote $=410$; percentages are weighted; bolded values indicate significant difference from large urban $(\mathrm{p}<0.05)$ 


\section{Figure 4. Social Impacts}

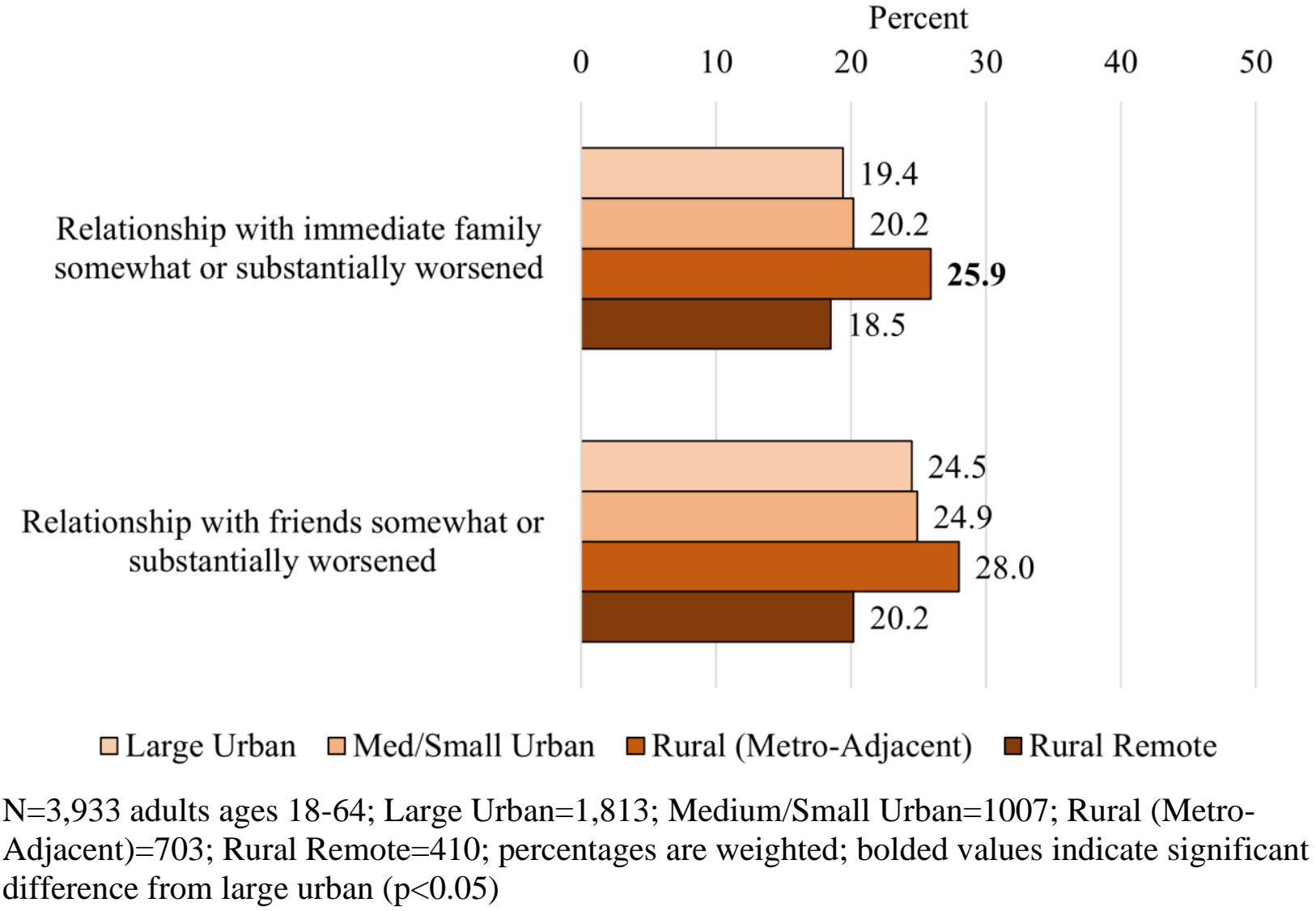


Figure 5. Employment Impacts

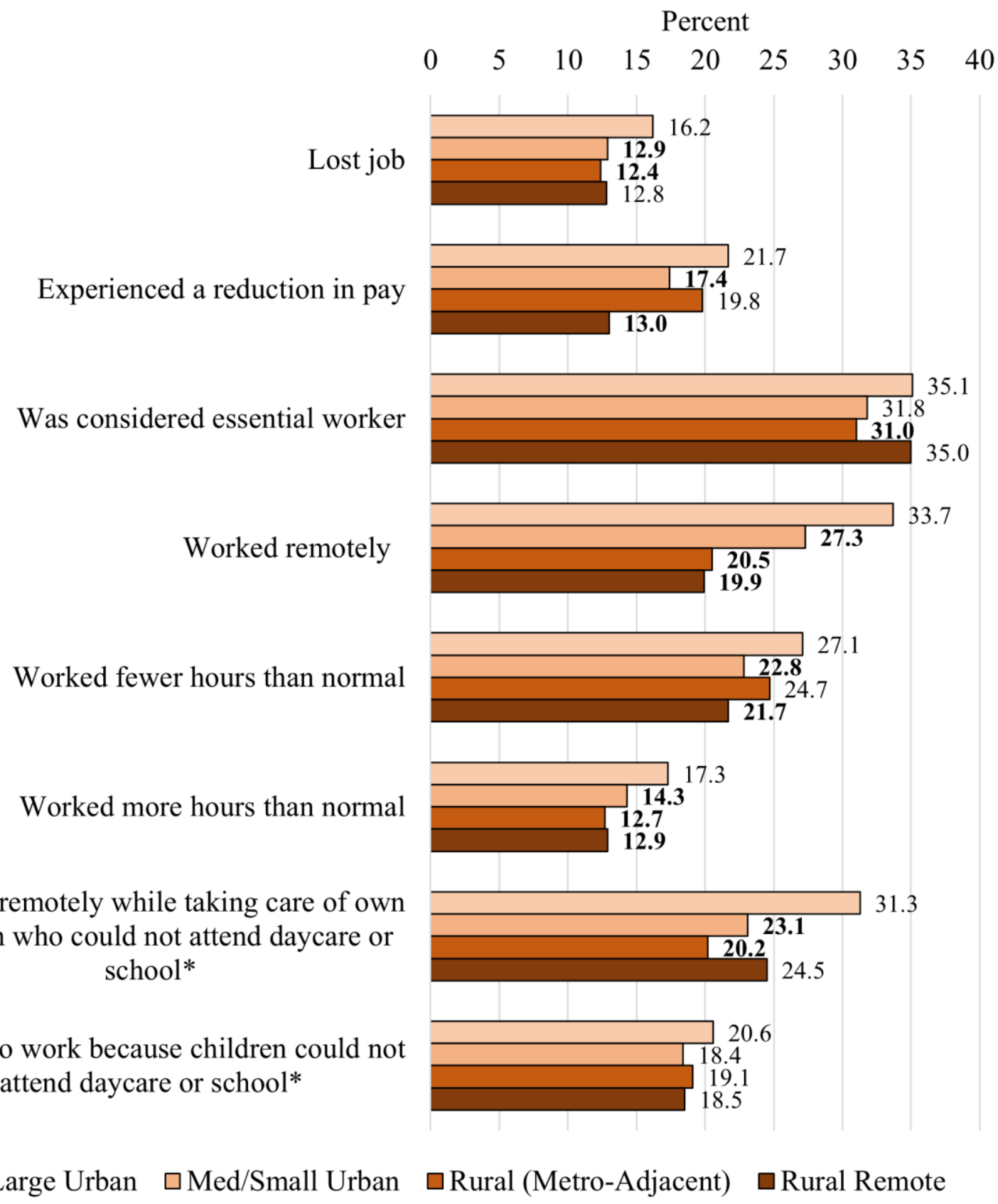

Worked remotely while taking care of own children who could not attend daycare or school*

Unable to work because children could not attend daycare or school*

$\mathrm{N}=3,933$ adults ages 18-64; Large Urban=1,813; Medium/Small Urban=1007; Rural (MetroAdjacent $)=703$; Rural Remote $=410$; percentages are weighted; bolded values indicate significant difference from large urban $(\mathrm{p}<0.05)$

*Analysis includes only respondents with children ages $<18$ in the household ( $\mathrm{N}=1,595$ adults ages 18-64; Large Urban=783; Medium/Small Urban=386; Rural (Metro-Adjacent)=269; Rural Remote $=157$ ) 
Figure 6. Financial Impacts

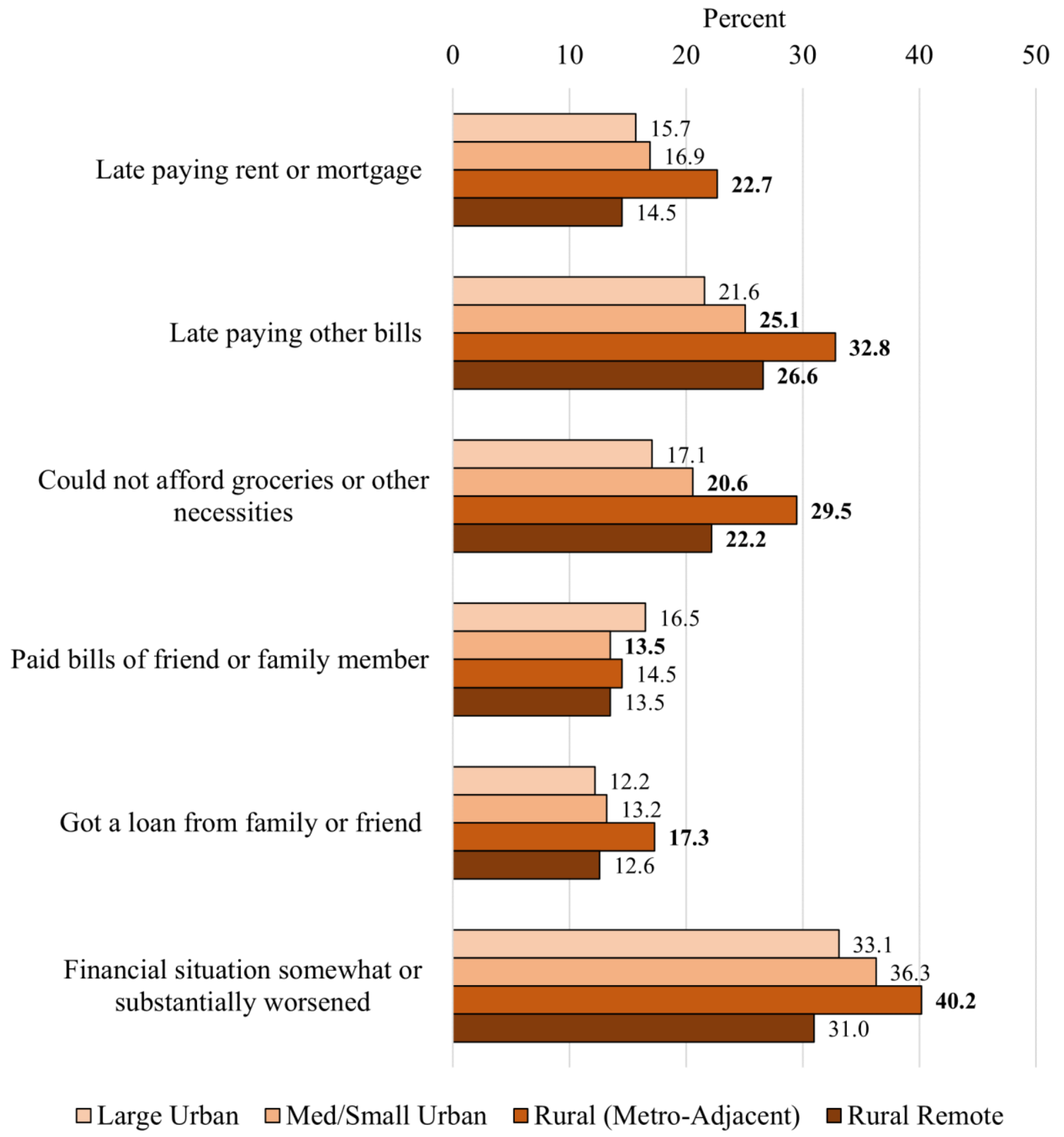

$\mathrm{N}=3,933$ adults ages 18-64; Large Urban=1,813; Medium/Small Urban=1007; Rural (MetroAdjacent $)=703$; Rural Remote $=410$; percentages are weighted; bolded values indicate significant difference from large urban $(\mathrm{p}<0.05)$ 
Table 2. Odds Ratios from Unadjusted Multilevel Logistic Regression Models Predicting COVID-19 Experiences and Impacts by Metro Status

Odds Ratios (95\% Confidence Intervals) Medium/Small Rural Metro-

Reference=large urban Urban Adjacent

Rural Remote

Global COVID-19 Impact

All things considered COVID-19 has had negative impact on my life

$\begin{array}{ccc}1.08 & 1.02 & 0.88 \\ (0.91 \text { to } 1.29) & (0.80 \text { to } 1.31) & (0.62 \text { to } 1.23)\end{array}$

\section{COVID-19 Exposure and Infection Experiences}

Received a coronavirus test

Tested positive for coronavirus

Hospitalized due to coronavirus

Close family member hospitalized due to coronavirus

Lived with someone who tested positive

Close family member or friend outside of household tested positive

Anyone in household had to quarantine due to exposure

Family member or friend died from coronavirus

$\underline{\text { Physical and Mental Health Impact }}$

Physical health somewhat or substantially worse due to COVID-19

Mental health somewhat or substantially worse due to COVID-19

$\begin{array}{ccc}0.83^{*} & 0.91 & 0.82 \\ (0.69 \text { to } 0.99) & (0.70 \text { to } 1.17) & (0.57 \text { to } 1.18) \\ 0.86 & 1.31 & 1.42 \\ (0.64 \text { to } 1.16) & (0.88 \text { to } 1.94) & (0.83 \text { to } 2.41) \\ 0.54^{\wedge} & 0.46 & 0.85 \\ (0.27 \text { to } 1.08) & (0.14 \text { to } 1.53) & (0.23 \text { to } 3.19) \\ 0.88 & 1.58^{*} & 1.12 \\ (0.66 \text { to } 1.18) & (1.10 \text { to } 2.27) & (0.64 \text { to } 1.96) \\ 1.42^{\wedge} & 1.88^{* *} & 1.56 \\ (0.99 \text { to } 2.04) & (1.18 \text { to } 3.01) & (0.79 \text { to } 3.09) \\ 1.08 & 1.43^{* *} & 1.25 \\ (0.90 \text { to } 1.31) & (1.10 \text { to } 1.84) & (0.87 \text { to } 1.79) \\ 0.99 & 1.25 & 1.46^{\wedge} \\ (0.79 \text { to } 1.25) & (0.91 \text { to } 1.72) & (0.96 \text { to } 2.24) \\ 1.22 & 1.29 & 1.36 \\ (0.93 \text { to } 1.60) & (0.90 \text { to } 1.85) & (0.68 \text { to } 1.90) \\ 1.09 & & \\ (0.90 \text { to } 1.31) & (0.92 \text { to } 1.55) & (0.64 \text { to } 1.34) \\ 1.19^{\wedge} & 1.19 & 1.08\end{array}$


Couldn't see the doctor due to COVID19

Sought treatment for anxiety or depression due to COVID-19

Depression (Scored 3 or higher on combined depression PHQ-2)

Anxiety (Scored 3 or higher on combined anxiety PHQ-2)

Social Impacts

Relationship with immediate family worsened

Relationship with friends worsened

\section{Employment Impacts}

Lost job

Experienced a reduction in pay

Was considered essential worker

Worked remotely

Worked fewer hours than normal

Worked more hours than normal

Worked remotely while taking care of own children who could not attend daycare or school ${ }^{\mathrm{a}}$

\begin{tabular}{|c|c|c|}
\hline (1.00 to 1.42 ) & (0.93 to 1.52$)$ & (0.77 to 1.53$)$ \\
\hline 0.97 & 0.91 & 0.82 \\
\hline (0.77 to 1.21$)$ & (0.66 to 1.26$)$ & (0.52 to 1.31$)$ \\
\hline 1.12 & $1.55^{* *}$ & 1.35 \\
\hline (0.90 to 1.38$)$ & (1.17 to 2.07 ) & (0.90 to 2.03 ) \\
\hline $1.23^{*}$ & $1.36 *$ & 1.32 \\
\hline (1.02 to 1.47$)$ & (1.05 to 1.74$)$ & (0.93 to 1.87 ) \\
\hline $1.20 *$ & $1.60 * * *$ & $1.38^{\wedge}$ \\
\hline (1.00 to 1.45$)$ & (1.24 to 2.05$)$ & (0.97 to 1.95$)$ \\
\hline 1.02 & $1.42 *$ & 0.94 \\
\hline (0.83 to 1.27$)$ & (1.07 to 1.89 ) & (0.62 to 1.45$)$ \\
\hline 1.02 & 1.19 & 0.77 \\
\hline (0.85 to 1.23$)$ & (0.91 to 1.56$)$ & (0.51 to 1.17$)$ \\
\hline $0.79^{\wedge}$ & 0.77 & 0.80 \\
\hline (0.62 to 1.00$)$ & (0.54 to 1.10$)$ & (0.49 to 1.32$)$ \\
\hline $0.80 *$ & 0.95 & $0.57 *$ \\
\hline (0.66 to 0.97$)$ & (0.71 to 1.27$)$ & (0.36 to 0.92$)$ \\
\hline 0.89 & 0.87 & 1.03 \\
\hline (0.74 to 1.06$)$ & (0.67 to 1.12 ) & (0.73 to 1.46$)$ \\
\hline $0.84^{\wedge}$ & $0.58 * * *$ & $0.56^{* *}$ \\
\hline (0.69 to 1.01$)$ & $(0.44$ to 0.78$)$ & (0.37 to 0.84$)$ \\
\hline 0.89 & 1.01 & 0.85 \\
\hline (0.74 to 1.09$)$ & (0.77 to 1.33$)$ & (0.57 to 1.27$)$ \\
\hline $0.84^{\wedge}$ & $0.73^{\wedge}$ & 0.74 \\
\hline (0.68 to 1.03$)$ & (0.53 to 1.26$)$ & (0.46 to 1.19$)$ \\
\hline 0.80 & $0.67^{\wedge}$ & 0.84 \\
\hline
\end{tabular}


Unable to work because children could not attend daycare or school ${ }^{\mathrm{a}}$

\section{$\underline{\text { Financial Impacts }}$}

Late paying other bills

Could not afford groceries or other necessities

Paid bills of friend or family member

Got a loan from family or friend

Financial situation worsened
Late paying rent or mortgage

\begin{tabular}{ccc}
$(0.59$ to 1.08$)$ & $(0.42$ to 1.07$)$ & $(0.45$ to 1.58$)$ \\
0.89 & 0.97 & 0.92 \\
$(0.64$ to 1.25$)$ & $(0.60$ to 1.59$)$ & $(0.46$ to 1.85$)$ \\
& & \\
1.14 & $1.64 * *$ & 0.97 \\
$(0.89$ to 1.40$)$ & $(1.22$ to 2.21$)$ & $(0.61$ to 1.56$)$ \\
$1.22^{\wedge}$ & $1.82 * * *$ & 1.38 \\
$(0.99$ to 1.51$)$ & $(1.39$ to 2.40$)$ & $(0.93$ to 2.03$)$ \\
$1.26 *$ & $2.01 * * *$ & 1.38 \\
$(1.00$ to 1.58$)$ & $(1.51$ to 2.69$)$ & $(0.90$ to 2.10$)$ \\
0.94 & 1.02 & 0.95 \\
$(0.74$ to 1.19$)$ & $(0.73$ to 1.43$)$ & $(0.58$ to 1.53$)$ \\
1.18 & $1.67 * *$ & 1.17 \\
$(0.91$ to 1.52$)$ & $(1.20$ to 2.33$)$ & $(0.71$ to 1.93$)$ \\
1.12 & $1.33 *$ & 0.89 \\
$(0.93$ to 1.33$)$ & $(1.04$ to 1.71$)$ & $(0.62$ to 1.28$)$ \\
\hline
\end{tabular}

Note: Multilevel random intercept models with individuals nested within counties and counties nested within states. The models do not include any covariates.

${ }^{\wedge} \mathrm{p}<0.10 ;{ }^{*} \mathrm{p}<0.05 ; * * \mathrm{p}<0.01 ; * * * \mathrm{p}<0.001$

Weighted 
Table 3. Odds Ratios from Adjusted Multilevel Logistic Regression Models Predicting COVID-19 Experiences and Impacts by Metro Status

\begin{tabular}{|c|c|c|c|}
\hline & \multicolumn{3}{|c|}{ Odds Ratios (95\% Confidence Intervals) } \\
\hline & $\begin{array}{c}\text { Medium/Small } \\
\text { Urban } \\
\end{array}$ & $\begin{array}{c}\text { Rural Metro- } \\
\text { Adjacent } \\
\end{array}$ & $\begin{array}{c}\text { Rural } \\
\text { Remote } \\
\end{array}$ \\
\hline \multicolumn{4}{|l|}{ Global COVID-19 Impact } \\
\hline All things considered COVID-19 has had negative impact on my life & $\begin{array}{c}1.12 \\
(0.94 \text { to } 1.34)\end{array}$ & $\begin{array}{c}1.07 \\
(0.83 \text { to } 1.39)\end{array}$ & $\begin{array}{c}0.91 \\
(0.64 \text { to } 1.29)\end{array}$ \\
\hline \multicolumn{4}{|l|}{ COVID-19 Exposure and Infection Experiences } \\
\hline Received a coronavirus test & $\begin{array}{c}0.90 \\
(0.75 \text { to } 1.09)\end{array}$ & $\begin{array}{c}1.11 \\
(0.85 \text { to } 1.46)\end{array}$ & $\begin{array}{c}0.96 \\
(0.66 \text { to } 1.39)\end{array}$ \\
\hline Tested positive for coronavirus & $\begin{array}{c}0.97 \\
(0.71 \text { to } 1.32)\end{array}$ & $\begin{array}{c}1.56^{*} \\
(1.03 \text { to } 2.39)\end{array}$ & $\begin{array}{c}1.61 \\
(0.92 \text { to } 2.81)\end{array}$ \\
\hline Hospitalized due to coronavirus & $\begin{array}{c}0.63 \\
(0.31 \text { to } 1.29)\end{array}$ & $\begin{array}{c}0.64 \\
(0.18 \text { to } 2.29)\end{array}$ & $\begin{array}{c}1.17 \\
(0.29 \text { to } 4.68)\end{array}$ \\
\hline Close family member hospitalized due to coronavirus & $\begin{array}{c}0.88 \\
(0.65 \text { to } 1.19)\end{array}$ & $\begin{array}{c}1.64 * \\
(1.11 \text { to } 2.42)\end{array}$ & $\begin{array}{c}1.15 \\
(0.64 \text { to } 2.05)\end{array}$ \\
\hline Lived with someone who tested positive & $\begin{array}{c}1.44^{\wedge} \\
(0.99 \text { to } 2.09)\end{array}$ & $\begin{array}{c}1.94 * \\
(1.17 \text { to } 3.21)\end{array}$ & $\begin{array}{c}1.63 \\
(0.80 \text { to } 3.32)\end{array}$ \\
\hline Close family member or friend outside of household tested positive & $\begin{array}{c}1.06 \\
(0.87 \text { to } 1.29)\end{array}$ & $\begin{array}{c}1.32 * \\
(1.00 \text { to } 1.73)\end{array}$ & $\begin{array}{c}1.19 \\
(0.82 \text { to } 1.74)\end{array}$ \\
\hline Anyone in household had to quarantine due to exposure & $\begin{array}{c}0.99 \\
(0.78 \text { to } 1.25)\end{array}$ & $\begin{array}{c}1.24 \\
(0.89 \text { to } 1.75)\end{array}$ & $\begin{array}{c}1.49^{\wedge} \\
(0.96 \text { to } 2.33)\end{array}$ \\
\hline Family member or friend died from coronavirus & $\begin{array}{c}1.24 \\
(0.94 \text { to } 1.54)\end{array}$ & $\begin{array}{c}1.38 \\
(0.94 \text { to } 2.02)\end{array}$ & $\begin{array}{c}1.23 \\
(0.72 \text { to } 2.09)\end{array}$ \\
\hline \multicolumn{4}{|l|}{ Physical and Mental Health Impact } \\
\hline Physical health somewhat or substantially worse due to COVID-19 & $\begin{array}{c}1.05 \\
(0.87 \text { to } 1.28)\end{array}$ & $\begin{array}{c}1.11 \\
(0.84 \text { to } 1.46)\end{array}$ & $\begin{array}{c}0.86 \\
(0.58 \text { to } 1.26)\end{array}$ \\
\hline Mental health somewhat or substantially worse due to COVID-19 & 1.13 & 1.03 & 0.95 \\
\hline
\end{tabular}


Couldn't see the doctor due to COVID19

Sought treatment for anxiety or depression due to COVID-19

Depression (Scored 3 or higher on combined depression PHQ-2)

Anxiety (Scored 3 or higher on combined anxiety PHQ-2)

Social Impacts

Relationship with immediate family worsened

Relationship with friends worsened

Employment Impacts

Lost job

Experienced a reduction in pay

Was considered essential worker

Worked remotely

Worked fewer hours than normal

Worked more hours than normal

Worked remotely while taking care of own children who could not attend daycare or school

\begin{tabular}{|c|c|c|}
\hline (0.94 to 1.36$)$ & (0.79 to 1.34$)$ & (0.66 to 1.37$)$ \\
\hline 0.99 & 0.91 & 0.78 \\
\hline (0.78 to 1.24$)$ & (0.65 to 1.28$)$ & (0.48 to 1.26$)$ \\
\hline 1.07 & $1.41 *$ & 1.21 \\
\hline (0.86 to 1.34$)$ & (1.03 to 1.92$)$ & (0.79 to 1.86$)$ \\
\hline 1.15 & 1.17 & 1.16 \\
\hline (0.95 to 1.39$)$ & (0.89 to 1.55$)$ & (0.80 to 1.68$)$ \\
\hline 1.07 & $1.27^{\wedge}$ & 1.10 \\
\hline (0.88 to 1.30$)$ & (0.97 to 1.67$)$ & (0.76 to 1.58$)$ \\
\hline 0.98 & $1.30^{\wedge}$ & 0.86 \\
\hline (0.78 to 1.22$)$ & $(0.96$ to 1.76$)$ & (0.55 to 1.34$)$ \\
\hline 1.05 & $1.30^{\wedge}$ & 0.84 \\
\hline (0.98 to 1.73$)$ & (0.98 to 1.73$)$ & (0.55 to 1.28$)$ \\
\hline $0.75 *$ & 0.78 & 0.82 \\
\hline (0.57 to 0.97$)$ & $(0.54$ to 1.14$)$ & (0.49 to 1.37$)$ \\
\hline 0.87 & 1.16 & 0.68 \\
\hline (0.72 to 1.06$)$ & $(0.85$ to 1.56$)$ & (0.42 to 1.11$)$ \\
\hline 1.00 & 1.15 & 1.35 \\
\hline (0.83 to 1.21$)$ & $(0.87$ to 1.52$)$ & (0.93 to 1.96$)$ \\
\hline 1.10 & 0.95 & 0.85 \\
\hline (0.90 to 1.34$)$ & $(0.69$ to 1.30$)$ & (0.55 to 1.32$)$ \\
\hline 1.00 & $1.29^{\wedge}$ & 1.03 \\
\hline (0.82 to 1.21$)$ & (0.96 to 1.72$)$ & (0.68 to 1.56$)$ \\
\hline 0.98 & 1.06 & 1.06 \\
\hline (0.79 to 1.20$)$ & $(0.75$ to 1.50$)$ & (0.65 to 1.72$)$ \\
\hline 1.12 & 1.12 & 1.27 \\
\hline
\end{tabular}


Unable to work because children could not attend daycare or school

\section{$\underline{\text { Financial Impacts }}$}

Late paying other bills

Could not afford groceries or other necessities

Paid bills of friend or family member

Got a loan from family or friend

Financial situation worsened
Late paying rent or mortgage

\begin{tabular}{ccc}
$(0.81$ to 1.55$)$ & $(0.66$ to 1.88$)$ & $(0.64$ to 2.53$)$ \\
0.91 & 0.94 & 0.80 \\
$(0.63$ to 1.30$)$ & $(0.54$ to 1.61$)$ & $(0.38$ to 1.70$)$ \\
1.07 & $1.55^{* *}$ & 0.92 \\
$(0.85$ to 1.36$)$ & $(1.12$ to 2.15$)$ & $(0.56$ to 1.50$)$ \\
1.14 & $1.61^{* *}$ & 1.22 \\
$(0.91$ to 1.41$)$ & $(1.20$ to 2.16$)$ & $(0.81$ to 1.83$)$ \\
1.10 & $1.57^{* *}$ & 1.06 \\
$(0.87$ to 1.40$)$ & $(1.14$ to 2.15$)$ & $(0.68$ to 1.66$)$ \\
1.08 & 1.33 & 1.20 \\
$(0.85$ to 1.39$)$ & $(0.93$ to 1.92$)$ & $(0.72$ to 2.00$)$ \\
1.16 & $1.65^{* *}$ & 1.15 \\
$(0.89$ to 1.51$)$ & $(1.16$ to 2.36$)$ & $(0.68$ to 1.94$)$ \\
1.05 & 1.19 & 0.80 \\
$(0.87$ to 1.26$)$ & $(0.91$ to 1.55$)$ & $(0.54$ to 1.16$)$ \\
\hline
\end{tabular}

Note: Multilevel random intercept models with individuals nested within counties and counties nested within states. Models control for respondent age, sex, race/ethnicity, marital status, number of adults and children in household, educational attainment, household income in 2019, homeownership, moved to county in past 12 months, political party, and 2020 Presidential vote.

${ }^{\wedge} \mathrm{p}<0.10 ; * \mathrm{p}<0.05 ; * * \mathrm{p}<0.01 ; * * * \mathrm{p}<0.001$

Weighted 


\section{Appendix A}

Table A1. Distribution of National Wellbeing Survey (NWS) Respondents Compared to U.S. Population ages 18-64

\begin{tabular}{|c|c|c|c|}
\hline & $\begin{array}{c}\text { NWS } \\
\text { Unweighted N } \\
(\%) \\
\end{array}$ & $\begin{array}{c}\text { NWS } \\
\text { Weighted } \\
\% \\
\end{array}$ & $\begin{array}{c}\text { U.S. Pop } \\
\text { (ages 18- } \\
64) \% \\
\end{array}$ \\
\hline \multicolumn{4}{|l|}{ SEX } \\
\hline Male & $1941(48.4)$ & 48.8 & 48.8 \\
\hline Female & $2040(50.8)$ & 50.4 & 50.4 \\
\hline Non-binary & $33(0.8)$ & 0.8 & 0.8 \\
\hline \multicolumn{4}{|l|}{ RACE/ETHNICITY } \\
\hline NH White & $2409(60.0)$ & 60.1 & 60.1 \\
\hline NH Black & $536(13.4)$ & 13.4 & 13.4 \\
\hline Hispanic & $748(18.6)$ & 18.5 & 18.5 \\
\hline Other Race & $321(8.0)$ & 8.0 & 8.0 \\
\hline \multicolumn{4}{|l|}{ AGE } \\
\hline $18-24$ & $632(15.7)$ & 15.7 & 15.6 \\
\hline $25-34$ & $872(21.7)$ & 21.6 & 21.6 \\
\hline $35-44$ & $833(20.8)$ & 20.5 & 20.5 \\
\hline $45-54$ & $869(21.7)$ & 21.9 & 21.9 \\
\hline $55-64$ & $808(20.1)$ & 20.2 & 20.2 \\
\hline \multicolumn{4}{|c|}{ EDUCATIONAL ATTAINMENT (ages 25-64) } \\
\hline$<$ High School & $133(3.9)$ & 10.9 & 10.9 \\
\hline HS Grad & $776(19.3)$ & 25.7 & 25.7 \\
\hline Some College/AA & $1100(32.5)$ & 29.9 & 29.9 \\
\hline 4-year degree+ & $1373(40.6)$ & 33.5 & 33.5 \\
\hline N/A (ages 18-24) $)^{\mathrm{a}}$ & 632 & -- & -- \\
\hline \multicolumn{4}{|l|}{ MARITAL STATUS } \\
\hline Never Married & $1323(33.0)$ & 35.1 & 36.2 \\
\hline Currently Married & $1761(43.9)$ & 42.0 & 49.2 \\
\hline Separated/Divorced & $503(12.5)$ & 12.2 & 12.9 \\
\hline Widowed & $102(2.5)$ & 2.6 & 1.6 \\
\hline Member of Unmarried Couple & $323(8.1)$ & 8.1 & $\mathrm{NA}^{\mathrm{b}}$ \\
\hline \multicolumn{4}{|l|}{ CHILDREN IN HOUSEHOLD } \\
\hline $\begin{array}{l}\text { No children under age } 18 \text { in } \\
\text { household }^{c}\end{array}$ & $2384(59.6)$ & 61.0 & 61.1 \\
\hline \multicolumn{4}{|c|}{ RURAL-URBAN CONTINUUM CODE } \\
\hline 1 & $1850(46.1)$ & 56.5 & 56.5 \\
\hline 2 & $715(17.8)$ & 21.0 & 21.0 \\
\hline 3 & $313(7.8)$ & 8.9 & 8.9 \\
\hline
\end{tabular}


Notes: Comparisons are based on American Community Survey estimates (2015-19)

${ }^{a}$ The survey weight is based on educational attainment only for ages 25-64.

${ }^{\mathrm{b}}$ The Census Bureau's marital status distribution does not include a breakdown for members of an unmarried couple.

${ }^{\mathrm{c}}$ The presence of children in household comparison comes from Current Population Survey (2018, https://www.census.gov/programs-surveys/cps/data/data-tools.html). The CPS provides data tables for related children under age 18 in the household. The NWS asks about the presence of any children under age 18 in the household. Therefore, these are not directly comparable. 
Table A2. Comparison of Means on Selected County-Level Characteristics for U.S. Counties Overall vs. Counties Represented in the National Wellbeing Survey

Counties

County Characteristic

All U.S. Represented in

Racial/Ethnic Composition

Percent non-Hispanic White

76.2

75.1

Percent non-Hispanic Black

8.9

9.9

Percent Hispanic

9.4

9.4

Age Composition

Percent under age 18

22.2

22.0

Percent age $65+$

18.8

18.1

Educational Composition

Percent 25+ with less than high school

13.1

12.8

Percent $25+$ with a 4 year college degree or more

22.0

Employment Composition

Percent employed (among ages 16+)

55.1

55.3

Percent not in labor force (among ages 16+)

41.6

41.1

Socioeconomic Composition

Median household income

53,475

55,284

Percent families in poverty

10.8

10.8

Percent owner-occupied housing units

71.6

70.2

Note: County characteristics are from the 2015-19 American Community Survey 
Table A3. Comparison of Prevalence Rates on Selected National Wellbeing Survey Items to Similar National Surveys

\begin{tabular}{lcc}
\hline Item & $\begin{array}{c}\text { NWS Weighted Estimate } \\
(95 \% \mathrm{CI})\end{array}$ & $\begin{array}{c}\text { Comparison Survey } \\
\text { Weighted Est. }\end{array}$ \\
\hline \hline
\end{tabular}

Ever been told by HCP that you have:

\begin{tabular}{|c|c|c|}
\hline $\begin{array}{l}\text { High cholesterol } \\
\text { Heart condition/disease }\end{array}$ & $\begin{array}{c}24.8 \%(23.5 \% \text { to } 26.2 \%) \\
5.8 \%(5.1 \% \text { to } 6.6 \%)\end{array}$ & $\begin{array}{l}21 \%^{\mathrm{a}} \\
6.1 \%^{\mathrm{a}}\end{array}$ \\
\hline \multicolumn{3}{|l|}{ Score of $3+$ on: } \\
\hline PHQ anxiety scale & $33.1 \%(31.6 \%$ to $34.5 \%)$ & $36.5 \%^{\mathrm{b}}$ \\
\hline PHQ depression scale & $31.9 \%(30.4 \%$ to $33.3 \%)$ & $30.3 \%^{b}$ \\
\hline $\begin{array}{l}\text { Someone in HH tested positive for } \\
\text { coronavirus }\end{array}$ & $5.4 \%(4.5 \%$ to $6.1 \%)$ & $4.0 \%{ }^{c}$ \\
\hline \multicolumn{3}{|l|}{ Due to COVID-19: } \\
\hline Lost Job & $17.7 \%(16.4 \%$ to $19.0 \%)$ & $17.1 \%^{\mathrm{d}}$ \\
\hline Reduction in pay & $26.0 \%(24.5 \%$ to $27.5 \%)$ & $27.8 \%^{\mathrm{d}}$ \\
\hline $\begin{array}{l}\text { Has given financial support to } \\
\text { friend or family member during } \\
\text { COVID-19 }\end{array}$ & $18.7 \%(17.4 \%$ to $20.0 \%)$ & $18.0 \%{ }^{\mathrm{c}}$ \\
\hline \multicolumn{3}{|c|}{$\begin{array}{l}\text { a. National Health Interview Survey, } 2018 \text { (ages 18-64) } \\
\text { b. U.S. Census Household Pulse Survey, Feb. 3-Mar 15, } 2021 \text { (ages 18-64) } \\
\text { c. American Family Survey, July 3-14, } 2020 \text { (ages 18+) } \\
\text { d. Urban Institute, March-April } 2020 \text { (ages 18-64) }\end{array}$} \\
\hline
\end{tabular}




\section{Appendix B}

Table B1. Descriptive Statistics for Sample Overall and by Metro Status

\begin{tabular}{|c|c|c|c|c|c|}
\hline & $\begin{array}{c}\text { Overall } \\
(\mathrm{N}=3,933) \\
\end{array}$ & $\begin{array}{l}\text { Large Urban } \\
(\mathrm{N}=1,813)\end{array}$ & $\begin{array}{c}\text { Med/Small } \\
\text { Urban } \\
(\mathrm{N}=1,007) \\
\end{array}$ & $\begin{array}{c}\text { Rural } \\
\text { (Metro- } \\
\text { Adjacent) } \\
(\mathrm{N}=703) \\
\end{array}$ & $\begin{array}{c}\text { Rural } \\
\text { Remote } \\
(\mathrm{N}=410) \\
\end{array}$ \\
\hline Age (in years) & $40.8(13.8)$ & $40.1(15.1)$ & $41.2(15.1)$ & $42.7(9.9)$ & $42.6(8.4)$ \\
\hline \multicolumn{6}{|l|}{ Sex } \\
\hline Male & 49.2 & 54.0 & 45.5 & 37.5 & 36.5 \\
\hline Female & 50.0 & 45.5 & 53.2 & 61.4 & 62.2 \\
\hline Nonbinary or other & 0.8 & 0.5 & 1.3 & 1.1 & 1.3 \\
\hline \multicolumn{6}{|l|}{ Race/Ethnicity } \\
\hline Non-Hispanic White & 60.4 & 52.8 & 63.4 & 86.3 & 85.2 \\
\hline Non-Hispanic Black & 13.0 & 15.0 & 13.2 & 4.1 & 4.3 \\
\hline Hispanic & 18.6 & 23.2 & 15.9 & 5.4 & 6.0 \\
\hline Other Race & 7.9 & 9.0 & 7.6 & 4.3 & 4.4 \\
\hline \multicolumn{6}{|l|}{ Marital Status } \\
\hline $\begin{array}{l}\text { of unmarried couple } \\
\text { Divorced, separated, }\end{array}$ & 50.5 & 50.6 & 49.0 & 52.1 & 55.0 \\
\hline or widowed & 14.7 & 12.9 & 14.5 & 23.6 & 19.2 \\
\hline Single, never married & 34.9 & 36.5 & 36.5 & 24.3 & 25.8 \\
\hline $\begin{array}{l}\text { Number of adults in } \\
\text { household }^{\mathrm{a}}\end{array}$ & $2.3(1.3)$ & $2.3(1.5)$ & $2.3(1.4)$ & $2.3(0.8)$ & $2.2(0.7)$ \\
\hline $\begin{array}{l}\text { Number of children in } \\
\text { household }^{\mathrm{b}}\end{array}$ & $0.73(1.09)$ & $0.75(1.19)$ & $0.69(1.17)$ & $0.69(0.81)$ & $0.75(0.76)$ \\
\hline
\end{tabular}

Household Income in 2019

Less than $\$ 25,000$

$\$ 25,000-50,000$

$\$ 50,000-74,999$

$\$ 75,000-99,999$

$\$ 100,000$ or more

Income missing

Educational

Attainment

Less than high

school

High school graduate

Some

college/Associates

degree

4-year college degree

or more
28.0

23.8

15.2

10.9

17.8

4.4

10.2

27.9

30.5

31.4
22.9

22.4

15.1

12.2

22.8

4.6

8.0

25.1

28.8

38.1
39.9

42.4

27.4

27.2

24.8

12.7

10.9

9.9

12.1

4.7

8.8

5.2

8.5

10.6

2.7

3.8 


\begin{tabular}{lccccc}
$\begin{array}{l}\text { Owns home } \\
\text { Lived in current } \\
\text { county for less than 1 }\end{array}$ & 49.4 & 50.0 & 47.9 & 50.4 & 50.2 \\
$\begin{array}{l}\text { year } \\
\text { Political party }\end{array}$ & 6.6 & 5.6 & 7.8 & 8.4 & 6.2 \\
$\quad$ & & & & & \\
$\quad \begin{array}{l}\text { Republican } \\
\text { Democrat }\end{array}$ & 26.0 & 22.6 & 28.5 & 33.3 & 38.5 \\
$\quad \begin{array}{l}\text { Independent/Other } \\
\text { 2020 Presidential }\end{array}$ & 39.8 & 46.2 & 33.2 & 26.7 & 29.4 \\
Vote & 31.2 & 38.3 & 40.0 & 32.1 \\
$\quad$ & & & & \\
Biden & 46.4 & 54.0 & 40.1 & 27.9 & 28.8 \\
$\quad \begin{array}{l}\text { Trump } \\
\text { Other Candidate }\end{array}$ & 28.0 & 23.5 & 31.7 & 39.0 & 37.5 \\
$\quad 1.8$ & 1.7 & 2.1 & 2.1 & 1.4 \\
$\quad$ Did not vote & 23.9 & 20.8 & 26.2 & 31.1 & 32.3 \\
\hline a top-coded at 10 & & & & \\
b top-coded at 5 & & &
\end{tabular}

\footnotetext{
${ }^{1}$ Qualtrics conducted extensive data quality checks. Surveys were checked for flatlining (i.e., straight-line answers on matrix questions), multiple-response (i.e., respondents selected almost all options in 'select-all-that-apply' questions); inattention (e.g., respondents took an inordinate amount of time to complete the survey, provided contradictory responses); speeding (took $<6$ minutes to complete the survey); garbage, suspicious, and profane responses to text questions; and demographic mismatches. Surveys were given an overall score based on these criteria. Surveys failing to meet Qualtrics' data quality threshold were dropped. Our research team conducted additional quality checks before accepting the final sample, including for example by aligning respondent age with answers about the timing of military service.

${ }^{2}$ Among those who reported voting in the 2020 Presidential election in the National Wellbeing Survey, the weighted share of reported votes for Biden was 71.4\% (ages 18-29), 63.5\% (ages 3049), and 50.8\% (ages 50-64). This is compared to 59\% (ages 18-29), 55\% (ages 30-49), and 47\% (ages 50-64) in a recent Pew Research Center report (https://www.pewresearch.org/politics/2021/06/30/behind-bidens-2020-victory/).
} 